\title{
VAMP8 is the V-SNARE that mediates basolateral exocytosis in a mouse model of alcoholic pancreatitis
}

\author{
Laura I. Cosen-Binker, ${ }^{1}$ Marcelo G. Binker, ${ }^{1}$ Cheng-Chun Wang, ${ }^{2}$ \\ Wanjin Hong, ${ }^{2}$ and Herbert Y. Gaisano' \\ ${ }^{1}$ Department of Medicine and Department of Physiology, University of Toronto and University Health Network, Toronto, Ontario, Canada. \\ 2Institute of Molecular and Cell Biology, Proteos, Singapore.
}

\begin{abstract}
In rodents and humans, alcohol exposure has been shown to predispose the pancreas to cholinergic or viral induction of pancreatitis. We previously developed a rodent model in which exposure to an ethanol (EtOH) diet, followed by carbachol (Cch) stimulation, redirects exocytosis from the apical to the basolateral plasma membrane of acinar cells, resulting in ectopic zymogen enzyme activation and pancreatitis. This redirection of exocytosis involves a soluble NSF attachment receptor (SNARE) complex consisting of syntaxin-4 and synapseassociated protein of $23 \mathrm{kDa}$ (SNAP-23). Here, we investigated the role of the zymogen granule (ZG) SNARE vesicle-associated membrane protein 8 (VAMP8) in mediating basolateral exocytosis. In WT mice, in vitro EtOH exposure or EtOH diet reduced Cch-stimulated amylase release by redirecting apical exocytosis to the basolateral membrane, leading to alcoholic pancreatitis. Further reduction of zymogen secretion, caused by blockade of both apical and basolateral exocytosis and resulting in a more mild induction of alcoholic pancreatitis, was observed in $\mathrm{Vamp8}^{-/-}$mice in response to these treatments. In addition, although ZGs accumulated in Vamp $8^{-/-}$acinar cells, ZG-ZG fusions were reduced compared with those in WT acinar cells, as visualized by electron microscopy. This reduction in ZG fusion may account for reduced efficiency of apical exocytosis in $\mathrm{Vamp8}^{-/-}$acini. These findings indicate that VAMP8 is the ZG-SNARE that mediates basolateral exocytosis in alcoholic pancreatitis and that VAMP8 is critical for ZG-ZG homotypic fusion.
\end{abstract}

\section{Introduction}

While considerable progress has been made in elucidating the mechanisms of injury caused by alcohol intoxication in several organs (liver, brain, and heart), there has only recently been an advance in unveiling the mechanisms of alcohol-mediated pancreatic injury $(1,2)$. In humans and rodent models, acute or chronic administration of alcohol to the exocrine pancreas did not cause substantial injury but did predispose the organ to triggering factors (e.g., postprandial cholinergic or cholecystokinin [CCK] stimulation, viral infection, high-fat diet) that then led to pancreatitis. An excellent model of alcoholic pancreatitis has emerged to simulate the human disease that involves chronic exposure to an alcohol diet followed by submaximal carbachol (Cch) or CCK stimulation (3).

In previous studies, we postulated a mechanism of acute pancreatitis caused by supramaximal CCK stimulation in rats, which involved the redirection of exocytosis that normally occurs at the apical plasma membrane (PM) to the basolateral PM surface, whereby ensuing ectopic zymogen enzyme activation in the interstitial space led to pancreatitis (4). Using a rat model of a 6 -week ethanol (EtOH) diet (ED) that resulted in blood alcohol levels equivalent to those seen in clinical intoxication (5), followed

Nonstandard abbreviations used: Atp, atropine; $\left[\mathrm{Ca}^{2+}\right]$, intracellular calcium concentration; Cch, carbachol; CCK, cholecystokinin; CD, control diet; ED, EtOH diet; EM, electron microscopy; EtOH, ethanol; KRH, Krebs-Ringer-HEPES; MIP-1 $\alpha$, macrophage inducing protein-1 $\alpha$; PM, plasma membrane; SNAP-23, synapse-associated protein of $23 \mathrm{kDa}$; SNARE, soluble NSF attachment receptor; Syn-4, syntaxin-4; VAMP, vesicle-associated membrane protein; v-SNARE, vesicle SNARE; ZG, zymogen granule. Conflict of interest: The authors have declared that no conflict of interest exists. Citation for this article: J. Clin. Invest. 118:2535-2551 (2008). doi:10.1172/JCI34672. by i.p. injections of submaximal concentrations of Cch or CCK simulating postprandial stimulation, we observed apical blockade and a redirection of exocytosis to the basolateral PM as well as pancreatitis (6-8). In those studies we began to reveal the putative molecules that mediate basolateral exocytosis, which we found to be consistent with the paradigm of the "SNARE hypothesis" ( 9 , 10). Specifically, Munc18c bound syntaxin-4 (Syn-4) on the basolateral PM, which prevented Syn-4 binding to cognate soluble NSF attachment receptor (SNARE) proteins $(4,6-8)$. ED or EtOH pretreatment of acini followed by submaximal Cch (6) or CCK stimulation $(7,8)$ induced PKC $\alpha$-mediated threonine phosphorylation of Munc18c, which caused its displacement from Syn-4, and activated Syn-4 assembly with synapse-associated protein of $23 \mathrm{kDa}$ (SNAP-23) and vesicle-associated membrane protein (VAMP) proteins to form the SNARE complex that we postulated to mediate basolateral exocytosis.

The distinct distribution of exocytotic syntaxins in the pancreatic acinar cell, including Syn-2 at the apical PM, Syn-3 on the zymogen granule $(Z G)$, and Syn-4 at the basolateral PM, dictates these respective target compartments for exocytotic fusion, which include apical exocytosis (ZG with the apical PM), homotypic ZG-ZG fusion, and basolateral exocytosis, respectively $(10,11)$. These syntaxins bind SNAP-23, which is present in all of these compartments $(10,12)$. Homotypic ZG-ZG fusion, observed as sequential exocytosis in pancreatic acinar cells, ensures that zymogen content empties out of a very limited apical PM space of the acinar cell with maximal efficiency during physiologic stimulation $(4,13)$. Supramaximal CCK or Cch stimulation, while causing apical blockade, remains fully capable of promoting homotypic ZG-ZG fusions (14). 
WT
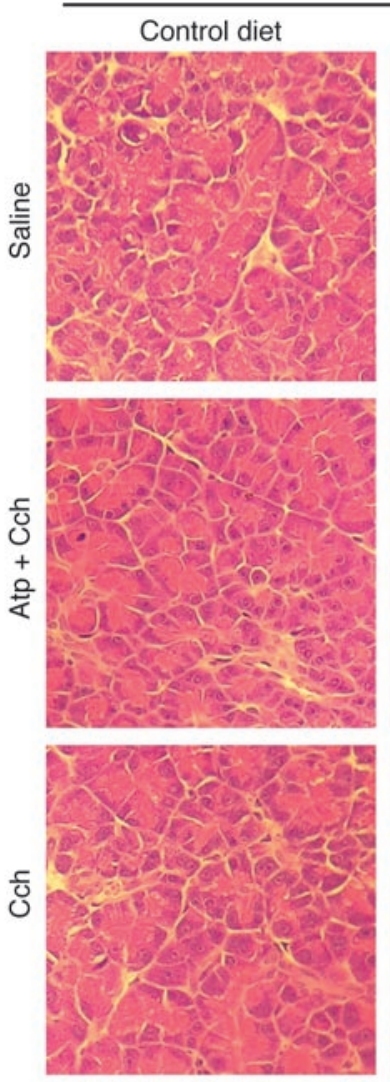

(1)
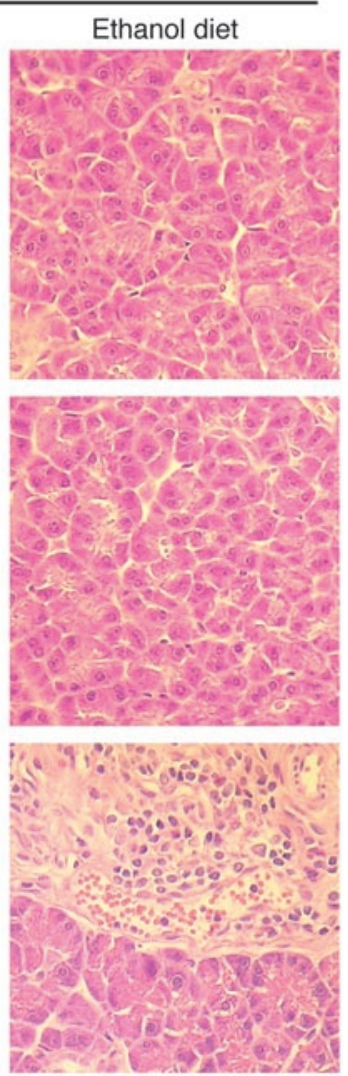

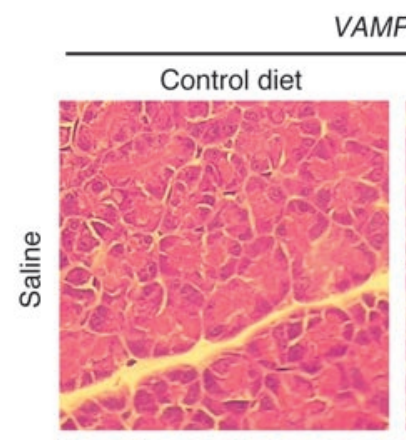

VAMP8-
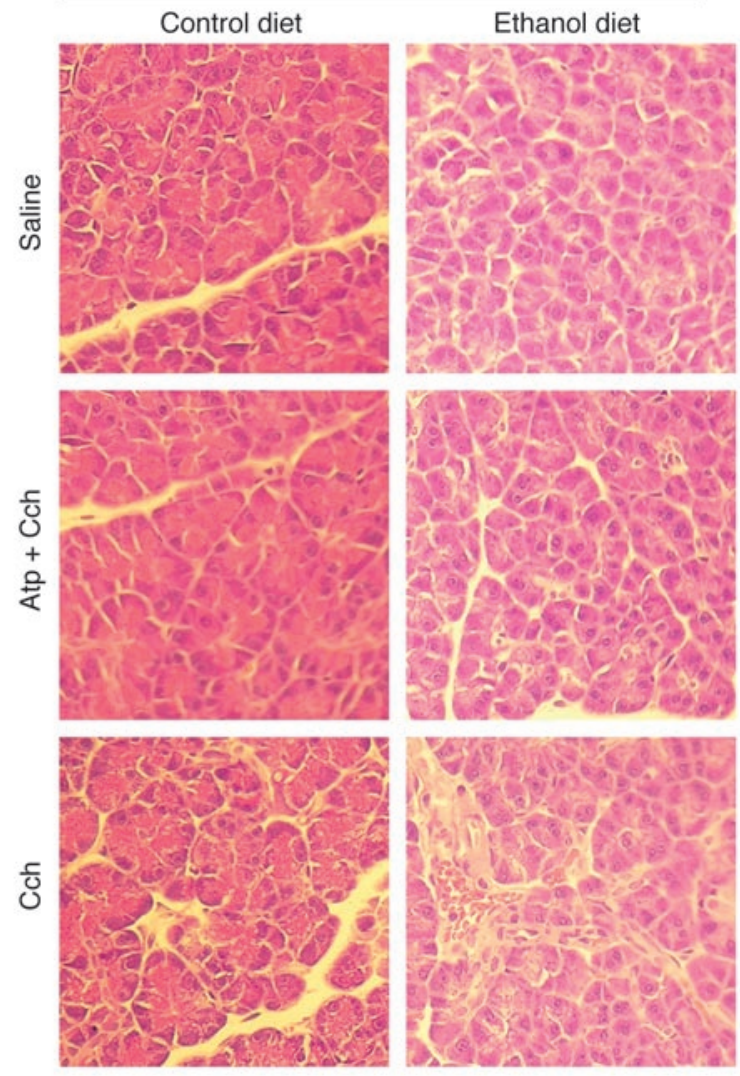

\section{Figure 1}

VAMP8 deletion reduces the severity of pancreatitis induced by ED plus Cch stimulation. Histology of pancreatic tissues. WT and Vamp8-/mice were pair-fed with either CD or ED for 6 weeks and then treated with 5 i.p. injections of saline, Cch $(50 \mu \mathrm{g} / \mathrm{kg} / \mathrm{h})$, or Atp (0.1 $\mu \mathrm{g} / \mathrm{kg} / \mathrm{h})$ followed by Cch $(50 \mu \mathrm{g} / \mathrm{kg} / \mathrm{h})$. Of note, the ED plus Cch group showed cytoplasmic vacuoles, leukocyte infiltration, hemorrhage, and necrosis. Original magnification, $\times 40$.

However, which ZG SNARE (VAMP2 or VAMP8) mediates membrane fusion at each of these compartments remains controversial $(10,15)$. VAMP2 was initially proposed to be the putative ZG SNARE, but complete cleavage of VAMP2 by tetanus toxin resulted in only $30 \%$ inhibition of $\mathrm{Ca}^{2+}$-stimulated enzyme secretion using a permeabilized acini assay $(16,17)$. A recent study using this same assay showed that VAMP8 antibodies block $\mathrm{Ca}^{2+}$-evoked enzyme secretion and suggested that VAMP8 might be the putative ZG SNARE mediating regulated apical exocytosis (18). Earlier reports had suggested a role of VAMP8 in homotypic fusion of early and late endosomes (19), but this was not confirmed in a report on Vamp8 gene deletion in mice (15). Instead, Vamp 8 deletion resulted in inhibition of agonist-stimulated secretion, not only in pancreatic acinar cells (15) but also in other exocrine tissues (20). While these reports collectively suggest the role of Vamp 8 in apical exocytosis, Vamp 8 deletion also abrogated supramaximal CCK-induced pancreatitis (15), which when taken in the context of our recent work $(4,6-8)$ would suggest a possible role for Vamp8 in basolateral exocytosis as well. Nonetheless, the precise role of Vamp 8 in each of these exocytotic compartments has not been unequivocally demonstrated.

Here, we examine the role of VAMP8 in exocytosis in each of these exocytotic compartments of the pancreatic acinar cell and in the context of the most frequent debilitating and often fatal disease that afflicts this cell type, alcoholic pancreatitis (21). Using VAMP8-null mice $(15,20)$ and the ED plus submaximal Cch-induced alcoholic pancreatitis model (6), we determine that VAMP8 is the putative vesicle SNARE (v-SNARE) that mediates basolateral exocytosis and whereby VAMP8 deletion ameliorates alcoholic pancreatitis. Remarkably, we also found VAMP8 to be the most probable v-SNARE for ZG-ZG homotypic fusion but not apical exocytosis per se, the latter remaining intact in VAMP8-null acinar cells.

\section{Results}

VAMP8 deletion reduces the severity of alcoholic pancreatitis and associated lung injury. Chronic exposure to EtOH through a 6-week ED (22) followed by a series of 5 hourly i.p. injections of submaximal Cch (Cch; $50 \mu \mathrm{g} / \mathrm{kg} / \mathrm{h})$ induces mild acute pancreatitis $(3,6)$, mimicking human alcoholic pancreatitis. A frequent fatal systemic complication of acute pancreatitis is acute lung injury (adult respiratory distress syndrome) $(21,23)$. We therefore examined whether VAMP8 deletion influenced pancreatic injury (Figure 1 and Table 1) or lung injury (Figure 2 and Table 2) in this ED plus Cch treatment model of alcoholic pancreatitis. Here, we compared ED with control diet (CD) in $\mathrm{Vamp}^{8^{+/+}}$(WT) and $\mathrm{Vamp}^{8^{-/-}}$mice subjected to 


\section{Table 1}

VAMP8 deletion reduces the severity of pancreatitis induced by ED plus Cch stimulation

\begin{tabular}{|c|c|c|c|c|c|c|c|c|}
\hline \multirow[b]{2}{*}{ Group } & \multicolumn{4}{|c|}{ WT } & \multicolumn{4}{|c|}{ Vamp8-/- } \\
\hline & Edema & Hemorrhage & $\begin{array}{l}\text { Leukocyte } \\
\text { infiltrate }\end{array}$ & Necrosis & Edema & Hemorrhage & $\begin{array}{l}\text { Leukocyte } \\
\text { infiltrate }\end{array}$ & Necrosis \\
\hline CD & $0 \pm 0$ & $0 \pm 0$ & $0 \pm 0$ & $0 \pm 0$ & $0 \pm 0$ & $0 \pm 0$ & $0 \pm 0$ & $0 \pm 0$ \\
\hline$C D+A t p+C c h$ & $0 \pm 0$ & $0 \pm 0$ & $0 \pm 0$ & $0 \pm 0$ & $0 \pm 0$ & $0 \pm 0$ & $0 \pm 0$ & $0 \pm 0$ \\
\hline$C D+C c h$ & $0 \pm 0$ & $0 \pm 0$ & $0 \pm 0$ & $0 \pm 0$ & $0 \pm 0$ & $0 \pm 0$ & $0 \pm 0$ & $0 \pm 0$ \\
\hline ED & $0.57 \pm 0.06$ & $0 \pm 0$ & $0.43 \pm 0.09$ & $0 \pm 0$ & $0.41 \pm 0.08$ & $0 \pm 0$ & $0.19 \pm 0.05$ & $0 \pm 0$ \\
\hline$E D+A t p+C c h$ & $0.60 \pm 0.08$ & $0 \pm 0$ & $0.55 \pm 0.05$ & $0 \pm 0$ & $0.45 \pm 0.12$ & $0 \pm 0$ & $0.31 \pm 0.09$ & $0 \pm 0$ \\
\hline$E D+C c h$ & $1.28 \pm 0.11$ & $3.09 \pm 0.08$ & $2.59 \pm 0.15$ & $3.22 \pm 0.18$ & $0.93 \pm 0.09^{A}$ & $1.35 \pm 0.11^{A}$ & $1.09 \pm 0.13^{\mathrm{A}}$ & $1.26 \pm 0.16^{A}$ \\
\hline
\end{tabular}

Histopathological score of pancreatic tissues shown in Figure 1 was graded from 0 to 4 ( 0 , absent; 1 , mild; 2, moderate; 3, severe; 4 , overwhelming), and was performed in a blinded manner by 2 independent observers. This shows that these pathological parameters were more severe in WT than in Vamp $8^{-/-}$ mice. Results are expressed as mean $\pm \mathrm{SD}$, corresponding to 4 mice per group from 3 independent experiments (12 experiments per condition). ${ }^{A} P<0.05$ compared with WT mice.

either Cch injections or saline injections (as control). As a further control, atropine (Atp) plus Cch administration (5 i.p. injections of Atp $0.1 \mathrm{mg} / \mathrm{kg} / \mathrm{h}$ prior to i.p. Cch injections) was used to block the development of pancreatitis. Figure 1 shows the representative histology, and Table 1 quantifies the pancreatic damage $(24,25)$. In WT and Vamp $8^{-/-}$mice, ED plus saline treatment induced very mild edema and leukocyte infiltration of the pancreatic tissues that were more prominent in the WT group. When these ED-fed groups were treated with Cch, the WT group developed moderate to severe pancreatitis characterized by parenchymal edema, necrosis with abundant leukocyte infiltration, fat necrosis, congested blood vessels within the peripancreatic fat, and hemorrhage $(24,25)$. Although all of these histologic changes of pancreatitis were also present in the Vamp $8^{-/-}$mice, these features were much milder in the Vamp $8^{-/-}$ group. Figure 2 and Table 2 show the lung histology (Figure 2 ) and quantification (Table 2). WT ED-fed Cch-treated group showed considerable lung tissue inflammatory changes of edema, leukocyte infiltration, congested capillaries, and hemorrhage. These changes were much milder in the Vamp $8^{-/-}$group. In the CD groups, pancreatic and lung histology were uniformly normal.

We then examined for markers of inflammation (pancreas and lung) and early tissue injury or necrosis (pancreas only). Myeloperoxidase activity and NF- $\mathrm{KB}$ (p50 and p65) activation are excellent markers of inflammation, which we observed in the pancreatic (Table 3) and lung tissues (Table 2). These parameters were below detection in CD-fed groups and became detectable in the pancreatic tissues of ED-fed saline-treated groups (higher in WT than Vamp $8^{-1-}$ mice). When ED-fed mice were treated with Cch, all these parameters showed a much higher increase in the WT group than in the Vamp $8^{-/-}$group in both pancreatic and lung tissues, which would correlate with the leukocyte infiltration seen on histology. When these mice were pretreated with Atp, all of these histologic changes and tissue inflammatory parameters caused by ED plus Cch treatment were either blocked or reduced.

Lipid peroxidation is an established mechanism of cellular injury (26). Cellular membranes are the major targets of lipid peroxides, resulting in alterations often associated with necrosis (26). To further evaluate the degree of pancreatic damage, we quantified the pancreatic levels of 2 biomarkers generated by lipid peroxidation, lipid hydroperoxides, and malondialdehyde (Table 3). In both WT and $\mathrm{Vamp}^{-/-}$mice, the ED increased the levels of these biomarkers when compared with the CD. Importantly, the values for the
ED plus Cch group showed significantly higher values in WT mice compared with Vamp8 $8^{-1-}$ mice.

Since acinar trypsinogen activation has been postulated to be a mechanism of alcoholic pancreatitis (27), we examined for pancreatic tissue trypsin activity (Table 3). Although trypsin activity was generally slightly lower in all the Vamp $8^{-/-}$groups, it was similarly increased in the ED plus Cch-treated groups (WT, $4.25 \pm 0.36$; Vamp $\left.8^{-1-}, 3.89 \pm 0.24 \mathrm{nM} / \mathrm{mg} \mathrm{DNA}\right)$. This would indicate that Vamp $8^{-/-}$acini retained the ability to activate trypsinogen, which presumably contributed to the milder residual pancreatitis (27) in the Vamp $8^{-1-}$ mice.

We then examined the circulatory clinical parameters of acute pancreatitis (Table 4). Serum alcohol levels in ED groups (WT and Vamp $8^{-/-}$mice) ranged from 25 to $34 \mathrm{mM}$ determined at 3 weeks and at sacrifice at 6 weeks, which are similar to those observed in human alcoholic intoxication (5) and those used in our in vitro studies (6-8). Serum amylase and lipase levels in CD- and ED-fed mice treated with saline were similarly low in WT and $\mathrm{Vamp}^{8^{-/-}}$mice. These serum enzyme levels were increased in CD-fed Cch-treated mice, being more elevated in WT than in $\mathrm{Vamp}^{-{ }^{--}}$mice. In ED-fed Cch-treated groups, WT mice exhibited a massive increase in serum amylase ( 10-fold) and lipase ( 250-fold) levels. These levels were much higher than those in Vamp $8^{-/-}$mice, which exhibited milder increases in amylase ( $\sim 5.7$-fold) and lipase ( 78 -fold) levels. Blood levels of the inflammatory mediators IL- 6 , TNF- $\alpha$, and macrophage inducing protein-1 $\alpha$ (MIP-1 $\alpha$ ) were detected in the ED-fed groups and were higher in WT compared with $V a m p 8^{-/-}$mice (Table 4). These systemic parameters indicate that the disease severity of acute pancreatitis was much milder in Vamp $8^{-/-}$mice than in WT mice but was not completely abrogated by the VAMP8 deletion.

Supramaximal cerulein-induced pancreatitis (see Methods) has been the classic model of pancreatitis $(1,2)$. Using this disease model, we observed profiles in the pancreatic and lung tissue and serum parameters in the WT and Vamp $8^{-/-}$mice (Supplemental Tables 1-4) that were remarkably similar to the ED plus Cch treatment (see above), wherein the Vamp $8^{-/-}$mice developed a much milder degree of pancreatitis than WT mice.

Since VAMP8 has been reported to directly mediate exocytosis in pancreatic acinar cells $(15,18,20)$, the abrogation of alcoholic pancreatitis by VAMP8 deletion would indicate that VAMP8-mediated exocytotic events contribute to this disease. In the following studies, we rigorously examined the role of VAMP8 in each of the 
WT
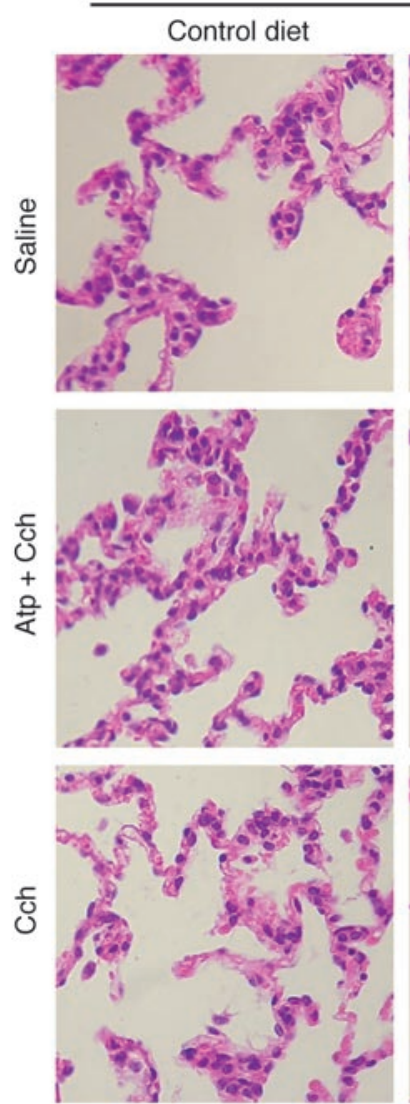

\section{Ethanol diet}
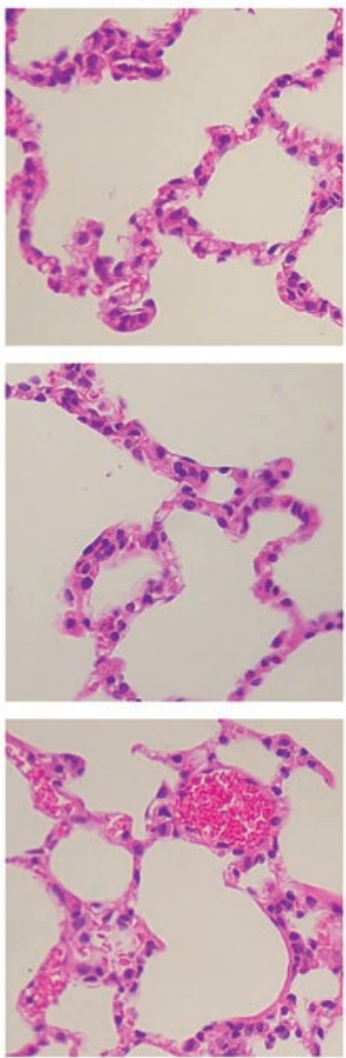

Figure 2

VAMP8 deletion reduces the severity of lung injury associated with alcoholic pancreatitis induced by ED plus Cch stimulation. Histology of lung tissues. WT and Vamp8 ${ }^{-1-}$ mice were treated exactly as described in Figure 1. Of note, the ED plus Cch group showed leukocyte infiltration and hemorrhage. Original magnification, $\times 40$.

exocytotic events of the pancreatic acinar cell in the context of this alcoholic pancreatitis model.

Regulated enzyme secretion is reduced but not ablated in Vamp8 $8^{-1-}$ acini and is further reduced by EtOH pretreatment. We first examined the effect of VAMP8 deletion on Cch- and EtOH-stimulated amylase secretion. As previously reported $(15,20)$, we confirmed the absence of VAMP8 protein in dispersed pancreatic acini of $\mathrm{Vamp}^{-/-}$mice (Figure $3 \mathrm{~A}$ and analysis in Supplemental Figure 1). Furthermore, VAMP2 protein expression was increased, which is consistent with the increase in number of ZGs. We have previously shown that $1 \mathrm{~h}$ is the optimal time for submaximal Cch $(3 \mu \mathrm{M})$ to maximally release amylase from dispersed pancreatic acini, and $1 \mathrm{~h}$ is the minimal preincubation time with $20 \mathrm{mM}$ EtOH, prior to addition of $3 \mu \mathrm{M}$ Cch, to achieve maximal inhibition of $3 \mu \mathrm{M}$ Cch-stimulated amylase secretion $(6,7)$. EtOH $20 \mathrm{mM}$ is a concentration well within the blood alcohol levels observed with clinical alcohol intoxication (5) and our alcoholic pancreatitis model (Table 4) but was insufficient to independently stimulate amylase secretion (6-8). VAMP8 neonatal pancreases were reported to exhibit higher amylase activity compared with normal neonatal pancreases (15). We therefore analyzed this in adult mice from both CD and ED groups, finding Vamp $8^{-1-}$ pancreases to exhibit a 2 -fold increase $(P<0.05)$ in amylase activity (in arbitrary units, $2.1 \pm 0.4$ and $2.3 \pm 0.4$, respectively) compared with WT pancreases $(1.0 \pm 0.2$ and $1.1 \pm 0.2$, respectively) (Figure $3 \mathrm{~B}$ ). Figure $3 \mathrm{C}$ examines
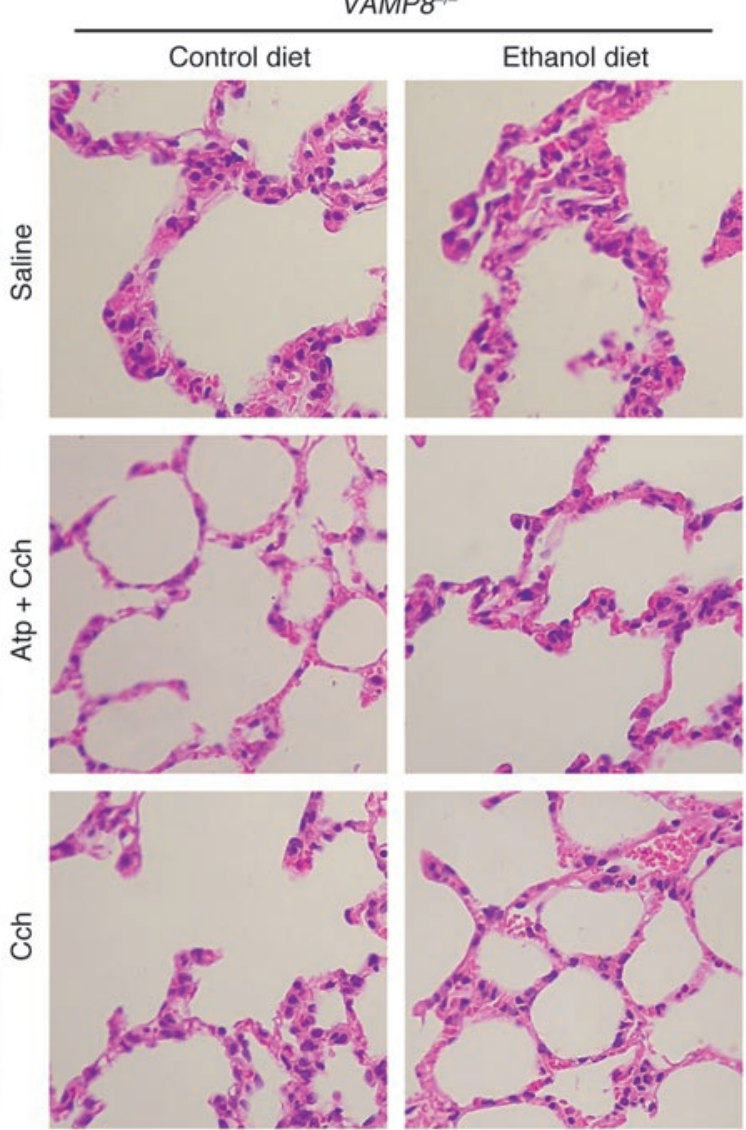
Table 2

VAMP8 deletion reduces the severity of lung injury associated with alcoholic pancreatitis induced by ED plus Cch stimulation

\begin{tabular}{|c|c|c|c|c|c|c|}
\hline Group & Edema & Hemorrhage & $\begin{array}{l}\text { Leukocyte } \\
\text { infiltrate }\end{array}$ & $\begin{array}{c}\text { MPO } \\
\text { (U/mg DNA) }\end{array}$ & $\begin{array}{c}\text { NF-KB (p65) } \\
(\mu \mathrm{g} / \mathrm{mg} \text { DNA) }\end{array}$ & $\begin{array}{l}\text { NF- } \kappa B \text { (p50) } \\
(\mu \mathrm{g} / \mathrm{mg} \text { DNA) }\end{array}$ \\
\hline \multicolumn{7}{|l|}{ WT } \\
\hline $\begin{array}{l}C D \\
C D+A t p+C c h \\
C D+C c h \\
E D \\
E D+A t p+C c h \\
E D+C c h\end{array}$ & $\begin{array}{c}0 \pm 0 \\
0 \pm 0 \\
0 \pm 0 \\
0 \pm 0 \\
0 \pm 0 \\
2.0 \pm 0.2\end{array}$ & $\begin{array}{c}0 \pm 0 \\
0 \pm 0 \\
0 \pm 0 \\
0 \pm 0 \\
0 \pm 0 \\
3.5 \pm 0.4\end{array}$ & $\begin{array}{c}0 \pm 0 \\
0 \pm 0 \\
0 \pm 0 \\
0 \pm 0 \\
0 \pm 0 \\
1.9 \pm 0.6\end{array}$ & $\begin{aligned} 0 & \pm 0 \\
0 & \pm 0 \\
0 & \pm 0 \\
0 & \pm 0 \\
0 & \pm 0 \\
11.0 & \pm 0.5\end{aligned}$ & $\begin{array}{c}B D \\
B D \\
B D \\
B D \\
B D \\
294 \pm 52\end{array}$ & $\begin{array}{c}B D \\
B D \\
B D \\
B D \\
B D \\
2.9 \pm 0.2\end{array}$ \\
\hline \multicolumn{7}{|l|}{ Vamp8-/- } \\
\hline $\begin{array}{l}C D \\
C D+A t p+C c h \\
C D+C c h \\
E D \\
E D+A t p+C c h \\
E D+C c h\end{array}$ & $\begin{aligned} 0 & \pm 0 \\
0 & \pm 0 \\
0 & \pm 0 \\
0 & \pm 0 \\
0 & \pm 0 \\
0.6 & \pm 0.2^{\mathrm{A}}\end{aligned}$ & $\begin{aligned} 0 & \pm 0 \\
0 & \pm 0 \\
0 & \pm 0 \\
0 & \pm 0 \\
0 & \pm 0 \\
1.2 & \pm 0.1^{\mathrm{A}}\end{aligned}$ & $\begin{aligned} 0 & \pm 0 \\
0 & \pm 0 \\
0 & \pm 0 \\
0 & \pm 0 \\
0 & \pm 0 \\
0.9 & \pm 0.1^{\mathrm{A}}\end{aligned}$ & $\begin{array}{c}0 \pm 0 \\
0 \pm 0 \\
0 \pm 0 \\
0 \pm 0 \\
0 \pm 0 \\
4.8 \pm 0.9 \mathrm{~A}\end{array}$ & $\begin{array}{c}\mathrm{BD} \\
\mathrm{BD} \\
\mathrm{BD} \\
\mathrm{BD} \\
\mathrm{BD} \\
95 \pm 19^{\mathrm{A}}\end{array}$ & $\begin{array}{c}\mathrm{BD} \\
\mathrm{BD} \\
\mathrm{BD} \\
\mathrm{BD} \\
\mathrm{BD} \\
1.3 \pm 0.1^{\mathrm{A}}\end{array}$ \\
\hline
\end{tabular}

Histopathological score of lung tissues shown in Figure 2 assessed in a blinded manner by 2 independent observers. Also shown are the lung tissue levels of inflammatory mediators. These pathological parameters were more severe in WT than in Vamp $8^{-/}$mice. Each sample was performed in triplicate. Results are expressed as mean $\pm \mathrm{SD}$, corresponding to 4 mice per group from 3 independent experiments (12 experiments per condition). BD, below detection limit; MPO, myeloperoxidase. ${ }^{A} P<0.05$ compared with WT mice. rable reduction of $49.2 \%$ and $50.7 \%$ in WT mice and $45.6 \%$ and $47.2 \%$ in Vamp8 $8^{-/-}$mice, respectively (data not shown). Supramaximal Cch is known to cause inhibition of secretion, which indeed was the case for $2 \mathrm{mM}$ Cch-stimulated release in WT $(10.3 \% \pm 0.9 \%)$ and Vamp $8^{-/-}$ acini $(3.6 \% \pm 0.7 \%)$. In contrast to submaximal and maximal Cch, EtOH pretreatment did not result in further inhibition of secretion from $2 \mathrm{mM}$ Cch-stimulated acini $(9.8 \% \pm 0.8 \%$ and $3.5 \% \pm 0.6 \%$ in WT and Vamp8 $8^{-1-}$, respectively).

As the above-described studies (see also Figure 3C) were are acute $\mathrm{EtOH}$ pretreatment studies, we examined the effects of chronic EtOH treatment with the 6-week ED (22) compared with CD (Figure $3 \mathrm{D})$ and then isolated the acini from these mice for secretory studies. In WT mice, $3 \mu \mathrm{M}$ Cch stimulated less amylase release from dispersed acini of ED-fed $(11.2 \% \pm 1.0 \%)$ versus CDfed mice $(17.4 \% \pm 1.2 \%)$, a $35.6 \%$ reduction $(P<0.05)$. In Vamp $8^{-/-}$mice, stimulated amylase secretion was observed to be uniformly reduced in all conditions compared with WT mice acini. Notably, $3 \mu \mathrm{M}$ Cch-stimulated release was reduced by $65 \%(P<0.05)$ in Vamp $8^{-/-}$acini $(6.1 \% \pm 0.6 \%)$ compared with WT acini in CD-fed mice $(17.4 \% \pm 1.2 \%)$. In Vamp $8^{-/-}$acini, ED caused a $38 \%(P<0.05)$ decrease in stimulated secretion compared with CD-fed acini $(3.8 \% \pm 0.6 \%$ vs. $6.1 \% \pm 0.6 \%$, respectively) and a $66 \%(P<0.05)$ decrease when compared with ED-fed WT acini $(3.8 \% \pm 0.6 \%$ vs. $11.2 \% \pm 1.0 \%$, respectively). Partial blockade by Atp in all of these conditions indicates that residual amylase release was specifically stimulated by Cch.

Calcium mobilization is not affected in Vamp $8^{-1-}$ acini. Calcium signaling is the major cell-signaling event that mediates pancreatic acinar secretion (28). We therefore examined whether calcium mobilization might be perturbed in Vamp $8^{-{ }^{-}}$acini, which might partly explain the reduction in secretion. Intracellular calcium concen-

\section{Table 3}

Pancreatic tissue parameters in ED plus low-dose Cch-induced alcoholic pancreatitis

\begin{tabular}{|c|c|c|c|c|c|c|}
\hline Group & $\begin{array}{c}\text { MPO } \\
\text { (U/mg DNA) }\end{array}$ & $\begin{array}{l}\text { Active trypsin } \\
\text { (nM/mg DNA) }\end{array}$ & $\begin{array}{l}\text { NF-кB (p65) } \\
(\mu \mathrm{g} / \mathrm{mg} \text { DNA) }\end{array}$ & $\begin{array}{l}\text { NF-кB (p50) } \\
(\mu \mathrm{g} / \mathrm{mg} \text { DNA) }\end{array}$ & $\begin{array}{c}\text { LPO } \\
\text { (nM/mg DNA) }\end{array}$ & $\begin{array}{c}\text { MDA } \\
(\mu \mathrm{M} / \mathrm{mg} \text { DNA })\end{array}$ \\
\hline \multicolumn{7}{|l|}{ WT } \\
\hline $\begin{array}{l}C D \\
C D+A t p+C c h \\
C D+C c h \\
E D \\
E D+A t p+C c h \\
E D+C c h\end{array}$ & $\begin{aligned} 0 & \pm 0 \\
0 & \pm 0 \\
0 & \pm 0 \\
1.53 & \pm 0.14 \\
1.49 & \pm 0.42 \\
16.78 & \pm 0.75\end{aligned}$ & $\begin{array}{l}0.12 \pm 0.05 \\
0.15 \pm 0.08 \\
0.29 \pm 0.11 \\
0.41 \pm 0.10 \\
0.49 \pm 0.13 \\
4.25 \pm 0.36\end{array}$ & $\begin{array}{c}B D \\
B D \\
B D \\
49 \pm 12 \\
53 \pm 9 \\
402 \pm 38\end{array}$ & $\begin{array}{c}B D \\
B D \\
B D \\
0.63 \pm 0.11 \\
0.69 \pm 0.10 \\
5.84 \pm 0.13\end{array}$ & $\begin{array}{c}\mathrm{BD} \\
\mathrm{BD} \\
\mathrm{BD} \\
18 \pm 5 \\
25 \pm 6 \\
327 \pm 29\end{array}$ & $\begin{array}{r}0.87 \pm 0.05 \\
0.91 \pm 0.08 \\
0.85 \pm 0.06 \\
2.18 \pm 0.19 \\
3.27 \pm 0.85 \\
23.25 \pm 0.16\end{array}$ \\
\hline \multicolumn{7}{|l|}{ Vamp8-1- } \\
\hline $\begin{array}{l}C D \\
C D+A t p+C c h \\
C D+C c h \\
E D \\
E D+A t p+C c h \\
E D+C c h\end{array}$ & $\begin{array}{c}0 \pm 0 \\
0 \pm 0 \\
0 \pm 0 \\
1.03 \pm 0.36 \\
1.11 \pm 0.45 \\
6.99 \pm 0.87 \mathrm{~A}\end{array}$ & $\begin{array}{l}0.07 \pm 0.02 \\
0.08 \pm 0.05 \\
0.25 \pm 0.09 \\
0.37 \pm 0.09 \\
0.39 \pm 0.07 \\
3.89 \pm 0.24 A\end{array}$ & $\begin{array}{c}B D \\
B D \\
B D \\
35 \pm 9 \\
39 \pm 12 \\
154 \pm 21^{A}\end{array}$ & $\begin{array}{c}B D \\
B D \\
B D \\
0.26 \pm 0.06 \\
0.33 \pm 0.09 \\
2.44 \pm 0.12^{A}\end{array}$ & $\begin{array}{c}B D \\
B D \\
B D \\
16 \pm 6 \\
21 \pm 5 \\
119 \pm 11 \text { A }\end{array}$ & $\begin{array}{r}0.81 \pm 0.04 \\
0.85 \pm 0.07 \\
0.92 \pm 0.08 \\
1.75 \pm 0.23 \\
2.48 \pm 0.74 \\
14.67 \pm 0.11^{A}\end{array}$ \\
\hline
\end{tabular}

AP $<0.05$ compared with WT mice. LPO, lipid hydroperoxides; MDA, malondialdehyde. 


\section{Table 4}

Serum parameters in ED plus low-dose Cch induced alcoholic pancreatitis

\begin{tabular}{|c|c|c|c|c|c|c|c|}
\hline Group & Amylase (IU/I) & Lipase (IU/I) & IL-6 (pg/ml) & TNF- $\alpha(\mathrm{pg} / \mathrm{ml})$ & MIP-1 $\alpha(p g / m I)$ & 3-wk ED & 6-wk ED \\
\hline WT & & & & & & BAC (mM) & BAC (mM) \\
\hline $\begin{array}{l}C D \\
C D+A t p+C c h \\
C D+C c h \\
E D \\
E D+A t p+C c h \\
E D+C c h\end{array}$ & $\begin{array}{r}474 \pm 9 \\
587 \pm 11 \\
943 \pm 19 \\
589 \pm 16 \\
622 \pm 12 \\
5,008 \pm 30\end{array}$ & $\begin{aligned} 16 & \pm 2 \\
35 & \pm 3 \\
147 & \pm 12 \\
27 & \pm 5 \\
42 & \pm 4 \\
3,955 & \pm 25\end{aligned}$ & $\begin{array}{c}\mathrm{BD} \\
\mathrm{BD} \\
\mathrm{BD} \\
64 \pm 7 \\
308 \pm 11 \\
1,074 \pm 48\end{array}$ & $\begin{array}{c}B D \\
B D \\
B D \\
13 \pm 3 \\
58 \pm 6 \\
498 \pm 34\end{array}$ & $\begin{aligned} 5 & \pm 1 \\
7 & \pm 2 \\
6 & \pm 1 \\
21 & \pm 3 \\
62 & \pm 14 \\
956 & \pm 23\end{aligned}$ & $\begin{array}{r}0 \pm 0 \\
0 \pm 0 \\
0 \pm 0 \\
31 \pm 3 \\
29 \pm 5 \\
32 \pm 4\end{array}$ & $\begin{aligned} 0 & \pm 0 \\
0 & \pm 0 \\
0 & \pm 0 \\
27 & \pm 4 \\
30 & \pm 5 \\
27 & \pm 6\end{aligned}$ \\
\hline \multicolumn{8}{|l|}{ Vamp8 $8^{--}$} \\
\hline $\begin{array}{l}C D \\
C D+A t p+C c h \\
C D+C c h \\
E D \\
E D+A t p+C c h \\
E D+C c h\end{array}$ & $\begin{aligned} 448 & \pm 9 \\
503 & \pm 11^{\mathrm{A}} \\
726 & \pm 15^{\mathrm{A}} \\
459 & \pm 17^{\mathrm{A}} \\
537 & \pm 21^{\mathrm{A}} \\
2,577 & \pm 42^{\mathrm{A}}\end{aligned}$ & $\begin{aligned} 19 & \pm 3 \\
35 & \pm 6 \\
115 & \pm 9^{A} \\
22 & \pm 2^{A} \\
28 & \pm 4^{A} \\
1,722 & \pm 23^{A}\end{aligned}$ & $\begin{array}{c}B D \\
B D \\
B D \\
54 \pm 9 \\
272 \pm 12 \\
685 \pm 17^{A}\end{array}$ & $\begin{array}{c}\mathrm{BD} \\
\mathrm{BD} \\
\mathrm{BD} \\
9 \pm 2 \\
50 \pm 3 \\
255 \pm 42^{\mathrm{A}}\end{array}$ & $\begin{aligned} 4 & \pm 1 \\
6 & \pm 1 \\
6 & \pm 1 \\
17 & \pm 2 \\
48 & \pm 7 \\
571 & \pm 26^{A}\end{aligned}$ & $\begin{array}{r}0 \pm 0 \\
0 \pm 0 \\
0 \pm 0 \\
29 \pm 3 \\
25 \pm 2 \\
27 \pm 5\end{array}$ & $\begin{array}{r}0 \pm 0 \\
0 \pm 0 \\
0 \pm 0 \\
34 \pm 4 \\
30 \pm 3 \\
30 \pm 5\end{array}$ \\
\hline
\end{tabular}

AP $<0.05$ compared with WT mice. BAC, blood alcohol concentration.

trations $\left(\left[\mathrm{Ca}^{2+}\right]_{\mathrm{i}}\right)$ in cell populations of pancreatic acini stimulated by secretagogues typically show a rapid increase to a peak followed by a somewhat lower sustained plateau phase (28). Figure 4 shows practically identical responses (peak and plateau phases of $\left[\mathrm{Ca}^{2+}\right]_{i}$ ) between WT and Vamp $8^{-/-}$acini stimulated with maximal Cch (80 $\mu \mathrm{M})$. This result indicates that the exocytotic defects in Vamp $8^{-/-}$ acini (Figure 3, C and D) may be attributed to defects in the membrane fusion machinery per se, and not to $\mathrm{Ca}^{2+}$ release.

Since exocytotic events in the pancreatic acinar cell occur at several sites, including apical PM, basal and lateral PM, and ZG-ZG fusion sites, we conducted a series of studies to determine precisely which of these exocytic sites are perturbed or preserved by the VAMP8 deletion and $\mathrm{EtOH}$ pretreatment. Of note, we very recently reported that acute alcohol pretreatment or chronic alcohol diet could redirect submaximal Cch-evoked (or CCK-evoked) apical exocytosis to the basolateral PM surface, culminating in alcoholic pancreatitis (6-8). This provided a further opportunity to examine whether VAMP8 plays a role in EtOH/Cch-mediated basolateral exocytosis as a possible underlying mechanism of alcoholic pancreatitis.

VAMP8 is required for basal PM exocytosis but not apical exocytosis. As previously reported (4, 6-8), we used the lipophilic FM1-43 dye, which fluoresces upon contact with the lipid PM, to image realtime exocytosis that occurs at the PM (29). Similar to our previous reports, submaximal Cch $(3 \mu \mathrm{M})$ evoked apical exocytosis in the WT acini, observed as a progressive increase in the size and intensity of fluorescence in the vicinity of the apical lumen, with some penetration into the deeper layers of ZGs within the apical poles $(4,6-8)$ (Figure 5, A and B). When WT acinus was pretreated with $20 \mathrm{mM}$ EtOH and then stimulated with $3 \mu \mathrm{M}$ Cch (Figure 5, C-E), apical exocytosis was blocked, and remarkably, exocytosis at the basal PM (Figure 5C) was observed as we recently reported (6-8). Figure 5C shows a timed sequence of static images of the 5 -cell acinus (arrow indicates the hot spot analyzed in Figure 5D), while Figure 5E shows 2 images (taken at $1 \mathrm{~min}$ and $30 \mathrm{~min}$ ) in pseudocolor to more clearly show the increased fluorescence of the basal PM hot spot. The data presented in Figure 5D show rhythmic excursions to similar peaks, indicating cycles of single ZG exocytosis and content emptying. We had previously shown that these FM1-43 hot spots colocalized with exocytosed amylase (4). As controls, $20 \mathrm{mM}$ EtOH alone $(1 \mathrm{~h})$ had no effect on exocytosis, and $1 \mu \mathrm{M}$ Atp pretreatment blocked both Cch-stimulated apical and $\mathrm{EtOH} / \mathrm{Cch}$-evoked basolateral exocytosis (data not shown).

In Vamp $8^{-1-}$ acini, we were surprised to observe apical exocytosis (Figure $5 \mathrm{~F}$ ), although the relative area and intensity of fluorescence were less $(21.3 \% \pm 1.8 \%, P<0.05)$ than those of WT acini (Figure $5 \mathrm{G}$ ). Nonetheless, this indicated that apical exocytosis, which is ZG fusion with the apical PM per se, was not blocked by the VAMP8 deletion. However, subsequent sequential exocytosis into the deeper layers of ZGs within the apical pole may have been reduced. With $20 \mathrm{mM}$ EtOH pretreatment followed by $3 \mu \mathrm{M}$ Cch stimulation (Figure 5, H and I), exocytosis was not detectable at the apical PM, but unlike WT acini, exocytosis was not observed at the basal PM, which would collectively account for the further reduction of amylase secretion shown in Figure 3. As expected, $20 \mathrm{mM}$ EtOH alone $(1 \mathrm{~h})$ had no effect on exocytosis in Vamp $8^{-/-}$ acini, and $1 \mu \mathrm{M}$ Atp pretreatment blocked Cch-stimulated apical exocytosis (data not shown). Taken together, these results indicate that VAMP8 is not required for apical exocytosis but is required for exocytosis at the basal PM.

$V A M P 8$ is required for exocytosis at the lateral $P M$ and for $Z G-Z G$ fusions. We had previously noted that FM1-43 had limited access to the lateral PM, even in small acini $(4,6-8)$. Since we previously observed by electron microscopy (EM) that EtOH/Cch treatment evoked extensive exocytosis at the lateral PM (6), we employed this strategy to examine whether VAMP8 plays a role in lateral PM exocytosis (Figure 6). EM also allowed for examination of ZGs inside the cell, including the abundance of ZGs and presence of ZG-ZG fusions (Figure 7). Exocytosis into the interstitial space and subsequent zymogen activation would contribute to the induction of pancreatitis $(14,30)$, and consequent morphologic changes of cell injury would also be observed. Conversely, abrogation of lateral exocytosis would be expected to reduce the pancreatic injury. To explore these possibilities, we examined the pancreatic tissues by EM from the ED- and CD-fed WT and Vamp $8^{-1-}$ mice described in Table 1. Quantification of these exocytotic events was performed on consecutive micrographs from 3 independent experiments, 
A

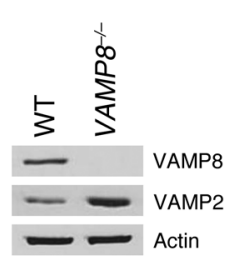

B

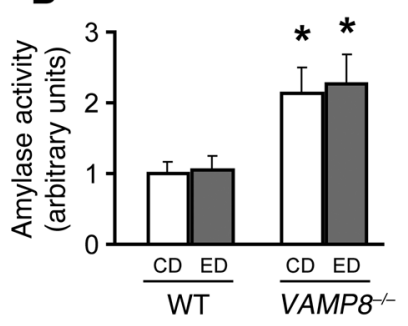

\section{C}
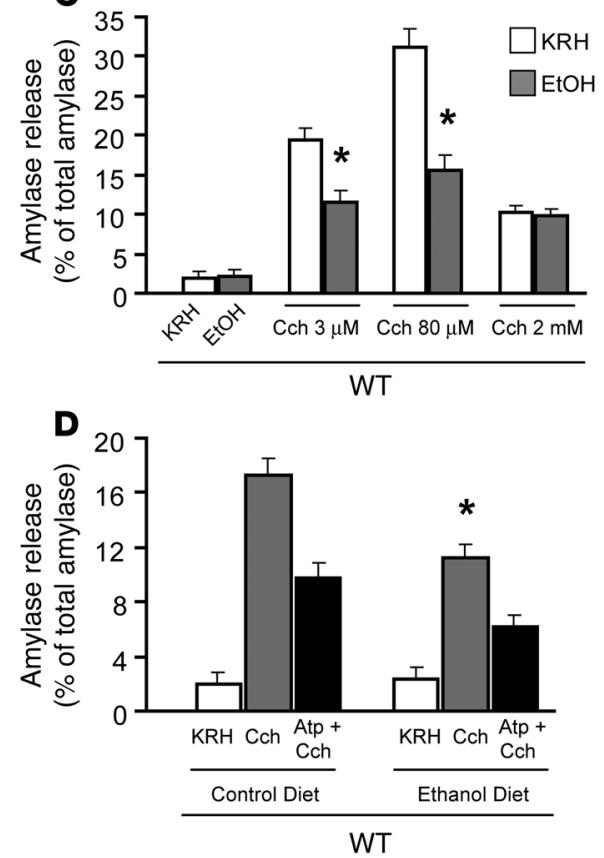
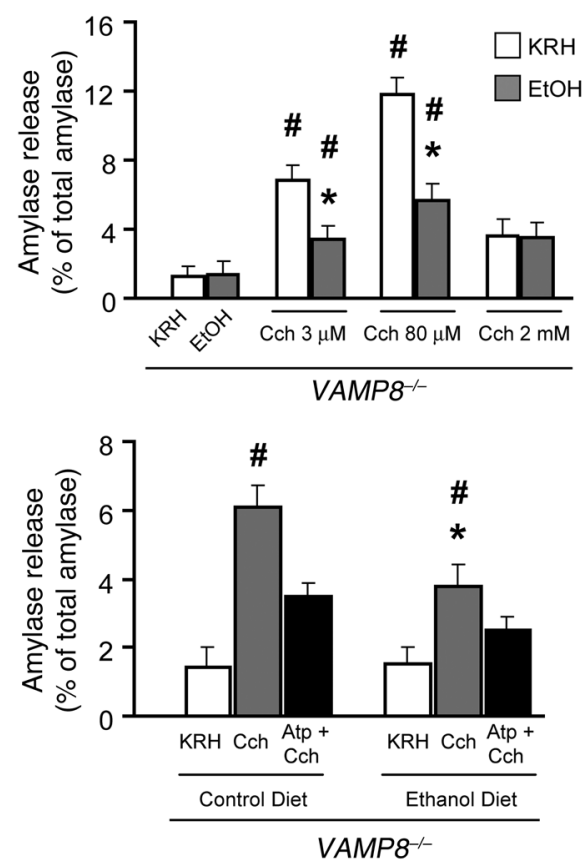

Figure 3

Regulated enzyme secretion is reduced but not ablated in Vamp8 $8^{-/}$acini and exhibits further reduction with alcohol pretreatment. (A) Western blot showing that VAMP8 is absent in Vamp8 ${ }^{-1-}$ mouse pancreatic tissue, while VAMP2 levels are increased. Protein (10 $\left.\mu \mathrm{g}\right)$ of each fraction was separated on SDS-PAGE and immunoblotted with antibodies to VAMP8, VAMP2, and actin. Representative of 3 independent experiments, $n=3$ (analysis shown in Supplemental Figure 1). (B) Accumulation of amylase in Vamp8 ${ }^{-/-}$pancreases. The amylase activity of adult WT and Vamp $8^{-/}$pancreases were determined and presented as arbitrary units. Each value is the mean \pm SD of triplicate samples per experiment from 5 independent experiments $(n=15)$. ${ }^{*} P<0.05$ compared with WT mice. (C) Effect of $20 \mathrm{mM} \mathrm{EtOH}(1 \mathrm{~h}$ preincubation) on submaximal $(3 \mu \mathrm{M}$, $1 \mathrm{~h})$, maximal $(80 \mu \mathrm{M}, 1 \mathrm{~h})$, and supramaximal $(2 \mathrm{mM}, 1 \mathrm{~h})$ Cch stimulated amylase release in WT and Vamp $8^{-/-}$acini. The amylase secreted into the media was determined and expressed as a percentage of the total cellular amylase of the respective sample. Each value is the mean $\pm \mathrm{SD}$ of triplicate samples per experiment from 5 independent experiments $(n=15)$. ${ }^{*} P<0.05$ compared with $\mathrm{KRH}$; $P<0.05$ compared with WT mice. (D) Effect of 6-wk ED on $3 \mu \mathrm{M}$ Cch-stimulated amylase release. Here, dispersed acini were obtained from CD- or ED-fed WT and Vamp8 ${ }^{-/-}$mice and then stimulated with $3 \mu \mathrm{M}$ Cch $(1 \mathrm{~h}), 1 \mu \mathrm{M}$ Atp $(1 \mathrm{~h})$ followed by $3 \mu \mathrm{M}$ Cch $(1 \mathrm{~h})$, or KRH (control). The amylase secreted into the media was determined and expressed as a percentage of the total cellular amylase of the respective sample. Each value is the mean $\pm \mathrm{SD}$ of triplicate samples per experiment from 5 independent experiments $(n=15)$. ${ }^{*} P<0.05$ compared with $\mathrm{CD}$; ${ }^{\#} P<0.05$ compared with WT mice.

each done in triplicate, with a total of 300 cells per condition analyzed. As shown in Figures 6 and 7, we only analyzed cells in which single sections cut across the full face of acini clearly identified the apical ductal lumen (indicated by asterisks in Figure 6) and junctional complexes (indicated by white arrows in Figure 6), which define the start of the lateral PM. From these ultrastructural studies, we noted the following major features.

In Figure 6, the first and most striking feature was the higher abundance of ZGs in the Vamp $8^{-/-}$acini. In saline-treated CD- and ED-fed mice, the Vamp $8^{-/-}$acini showed $95.0 \pm 6.2$ and $99.1 \pm 7.0 \mathrm{ZGs} /$ cell section, respectively, compared with WT acini with $45.0 \pm 5.3$ and $52.2 \pm 4.6 \mathrm{ZGs} /$ cell section, respectively. Their apical lumens were very similar in size (Vamp $8^{-/-}, 2.3 \pm 0.6 \mu \mathrm{m}^{2}$ [CD] vs. $2.5 \pm 0.7$ $\mu \mathrm{m}^{2}$ [ED]; WT, $2.5 \pm 0.6 \mu \mathrm{m}^{2}$ [CD] vs. $2.4 \pm 0.7 \mu \mathrm{m}^{2}$ [ED]). When $\mathrm{CD}$-fed mice were subjected to $3 \mu \mathrm{M}$ Cch stimulation, there was a relatively greater reduction in the number of ZGs in WT (30.2 \pm 4.1 ZGs/cell section, an $\sim 33 \%$ reduction) compared with Vamp $8^{-/-}$acini (71.1 $\pm 5.2 \mathrm{ZGs} /$ cell section, an $\sim 25 \%$ reduction) and a consequent increase in apical lumen sizes of $15.5 \pm 1.3 \mu \mathrm{m}^{2}$ and $14.3 \pm 1.2 \mu \mathrm{m}^{2}$ $(P<0.01)$, respectively. In these acini, ZGs appeared to be more packed into toward the apical lumens. This would indicate that apical exocytosis had occurred in both WT and Vamp $8^{-/-}$mice, albeit

\section{Figure 4}

VAMP8 deletion does not alter $\left[\mathrm{Ca}^{2+}\right]_{i}$ mobilization in Cch-stimulated pancreatic acini. Fura-2-loaded pancreatic acini from WT (black traces) and $\mathrm{Vamp}^{-/-}$(gray traces) mice were resuspended in solution $Q$ containing $1 \mathrm{mM} \mathrm{CaCl}_{2}$, incubated for $5 \mathrm{~min}$ with vehicle to obtain baseline values, and then stimulated with $80 \mu \mathrm{M}$ Cch. The arrow indicates the time at which the agonist was added. $\left[\mathrm{Ca}^{2+}\right]_{i}$ is expressed in $\mathrm{nM}$. This is representative of 3 independent experiments on different acini preparations.

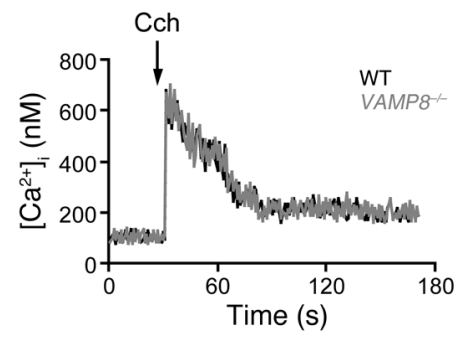




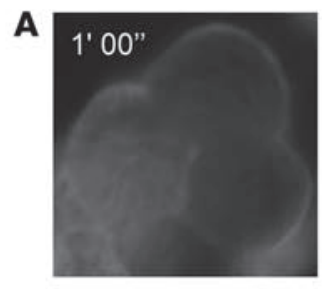

C
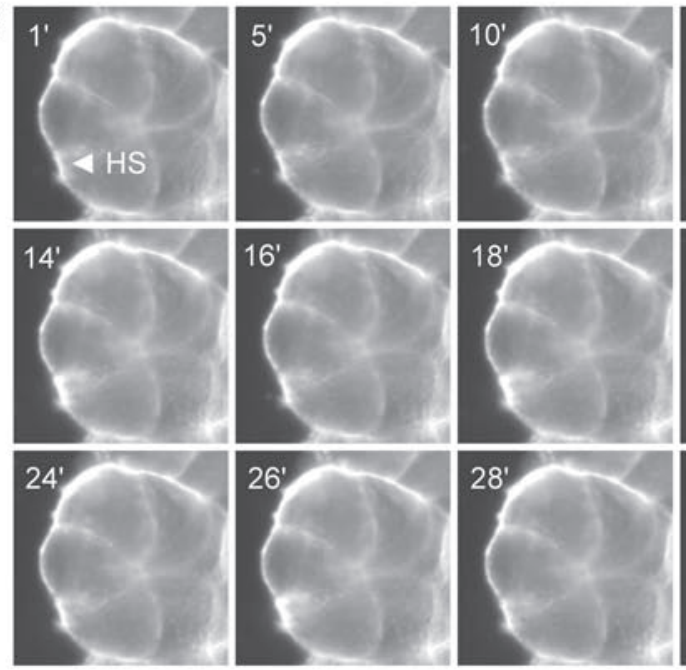

E
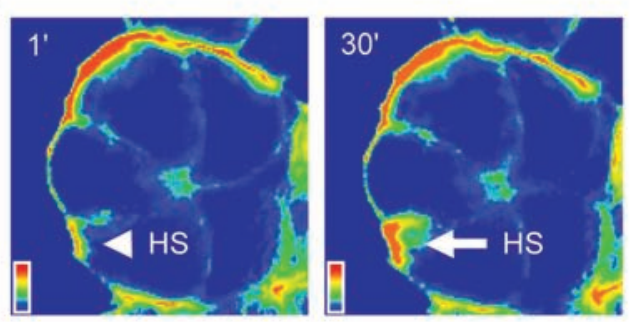

F
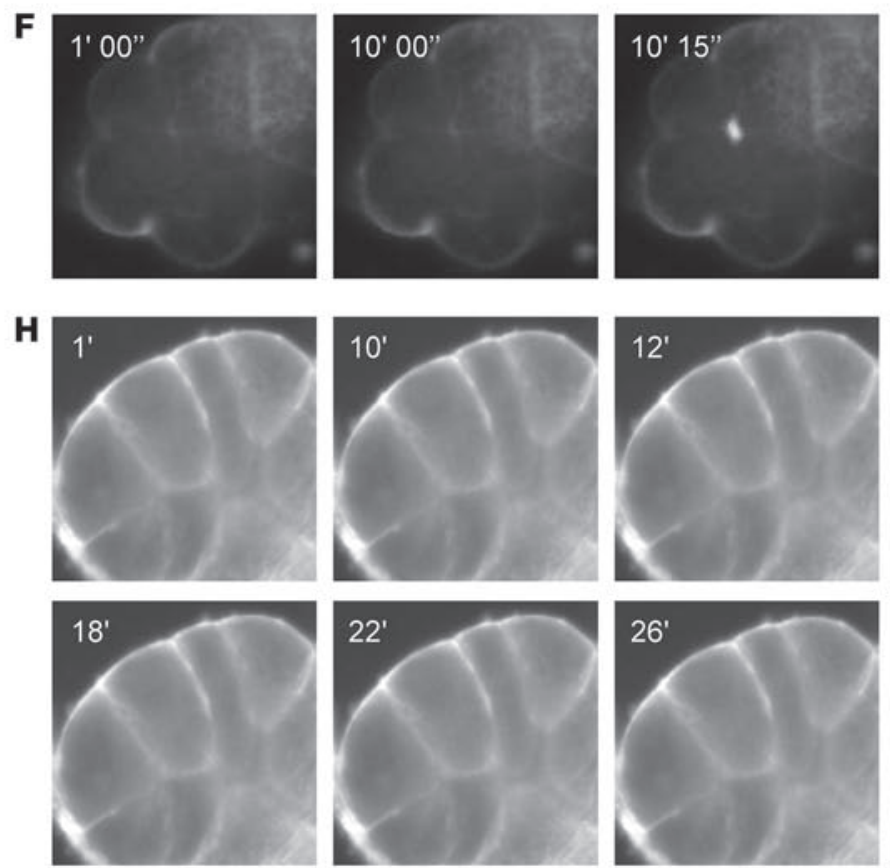

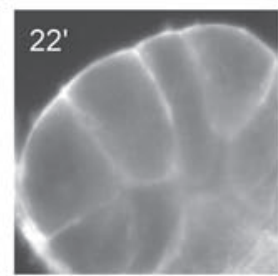

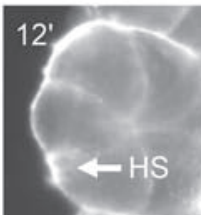
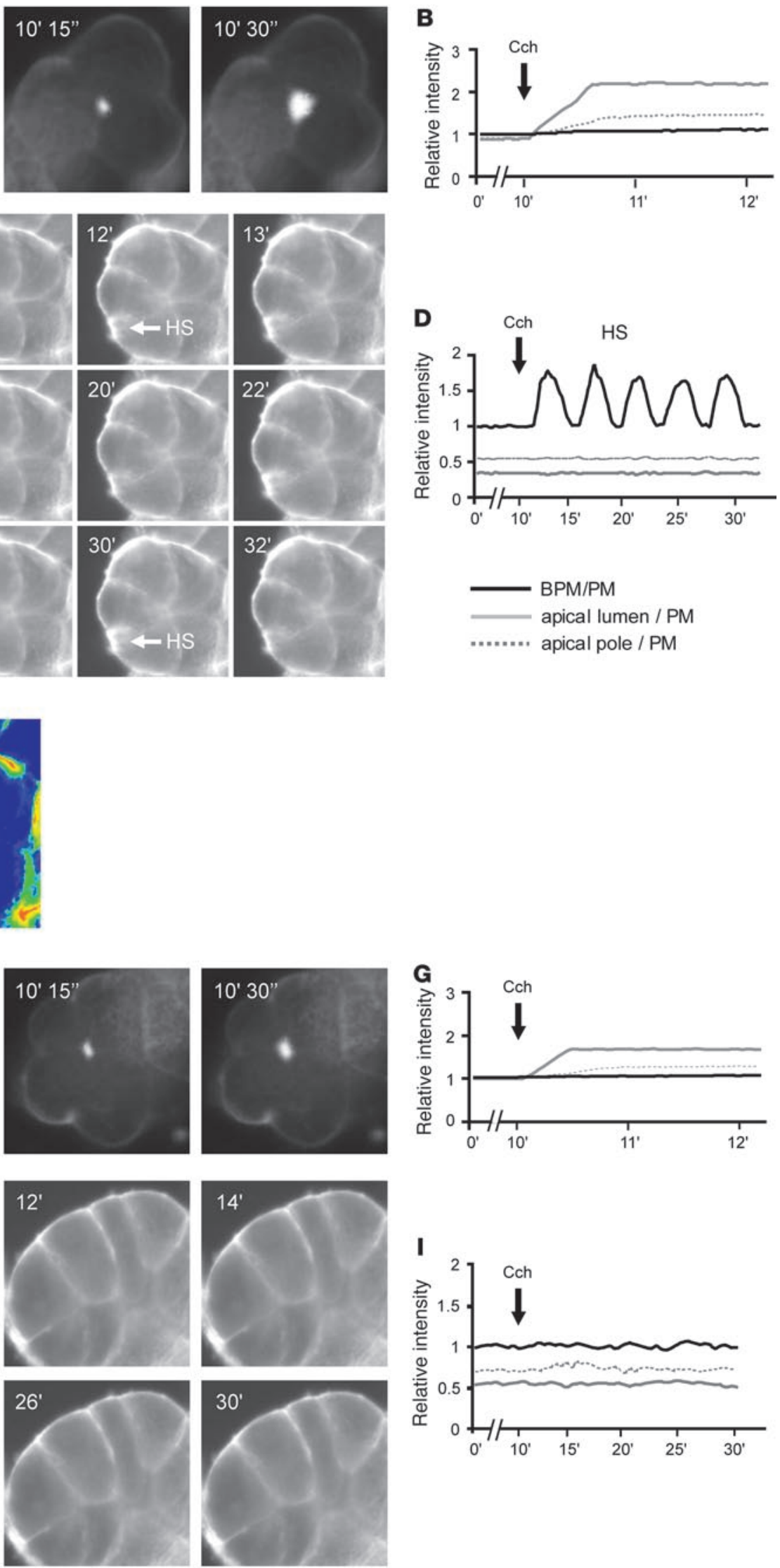


\section{Figure 5}

VAMP8 is required for EtOH to redirect Cch-evoked apical exocytosis to the acinar basal PM but is not required for Cch-stimulated apical exocytosis. A, C, $\mathbf{F}$, and $\mathbf{H}$ are representative sequences of static FM1-43 epifluorescence images, while B, D, G, and I are their respective real-time fluorescent tracings of each region (apical lumen, apical ZG pole, basal PM [BPM], or basal PM hot spots) of the acinus analyzed. (A) Increase in fluorescence at the apical lumen due to $3 \mu \mathrm{M}$ Cch stimulation in WT acini. (C) Appearance of a hot spot (HS) on the basal PM (indicated by arrows) upon $20 \mathrm{mM}$ EtOH (preincubation) plus $3 \mu \mathrm{M}$ Cch stimulation in WT acini. (E) Two images from $\mathbf{C}$ at $1 \mathrm{~min}$ and $30 \mathrm{~min}$ in pseudocolor to better visualize the fluorescence intensity changes of this hot spot at the basal PM (arrows) indicating that exocytosis was taking place. $(\mathbf{F})$ Increase in fluorescence at the apical lumen due to $3 \mu \mathrm{M}$ Cch stimulation in Vamp8 $8^{--}$acini. (H) No exocytosis occurred upon $20 \mathrm{mM}$ EtOH (preincubation) plus $3 \mu \mathrm{M}$ Cch stimulation in Vamp $8^{-/}$acini. In these studies, mice pancreatic acini were preincubated at $37^{\circ} \mathrm{C}$ with $2 \mu \mathrm{M}$ FM1-43 until stable fluorescence was attained on the PM and the indicated stimulation protocols carried out. Images were taken at $1 \mathrm{frame} / \mathrm{s}$ for $30 \mathrm{~min}$. The intensity for each hot spot was normalized to the intensity of the PM adjacent to it, where the relative intensity of basal PM/PM where no hot spot appeared was 1. All experiments shown are representatives of 3 experiments per condition performed on 4 acini isolations (12 experiments per condition). Full image sizes are as follows: $40 \mu \mathrm{m}^{2}$ (A), $50 \mu \mathrm{m}^{2}(\mathbf{C}, \mathbf{E}$, and $\mathbf{H})$, and $47 \mu \mathrm{m}^{2}(\mathbf{F})$.

moreso in WT acini. The second feature, therefore, is that VAMP8 deletion did not block apical exocytosis.

We then examined the ED-fed mice subjected to $3 \mu \mathrm{M}$ Cch stimulation. WT and Vamp $^{-/-}$acini showed increases in ZG abundance of $85.2 \pm 7.1 \mathrm{ZGs} /$ cell section and $235.9 \pm 9.4 \mathrm{ZGs} /$ cell section $(P<0.01)$, respectively. In WT acini, the ZGs were densely packed within the apical poles, whereas in the $V a m p 8^{-1-}$ acini, the more abundant ZGs were distributed beyond the apical regions and often appeared to fill up entire cells. Taken together, with their small apical lumens, which were minimally increased from basal states (WT, $2.9 \pm 0.6 \mu \mathrm{m}^{2} ; \operatorname{Vamp}^{8^{--}}, 3.2 \pm 0.8 \mu \mathrm{m}^{2}$ ), these results indicate a blockade of apical exocytosis by the $\mathrm{ED}$, which is the third feature. To demonstrate that these effects were indeed produced by Cch, we examined the effects of Atp pretreatment (5 i.p. injections of $1 \mu \mathrm{M} \mathrm{Atp} / \mathrm{kg} / \mathrm{h}$ ) prior to i.p. Cch injections, which would be expected to block the cholinergic actions. In WT acini, CD and ED groups showed $43.0 \pm 6.1 \mathrm{ZGs} /$ cell section and $50.3 \pm 4.1$ $\mathrm{ZGs} /$ cell section, with apical lumens of $2.8 \pm 0.6$ and $2.6 \pm 0.7 \mu \mathrm{m}^{2}$, respectively. In Vamp8 $8^{-/-}$acini, CD and ED groups showed $98.5 \pm 7.7$ $\mathrm{ZGs} /$ cell section and $112.2 \pm 6.9 \mathrm{ZGs} /$ cell section, with apical lumens of $2.6 \pm 0.6$ and $2.7 \pm 0.7 \mu \mathrm{m}^{2}$, respectively. These measurements are very similar to those found in the unstimulated states (see above) and therefore indicate that the apical blockade described above was indeed caused by Cch stimulation in the background of ED. All of the above data on the number of ZGs, their cellular distribution, and luminal surface areas are summarized and analyzed in Supplemental Figure 2, A, B, and F.

We then analyzed the $\mathrm{ZG}$ distribution and behavior along the lateral PM and interstitial space. ZGs were considered docked if they were touching the PM or within $50 \mathrm{~nm}$ of the PM. In WT ED-fed pancreatic tissues, Cch treatment induced a large number of ZGs to be docked onto the lateral PM, with many undergoing exocytosis. Morphometric analysis of these lateral exocytosis events showed that a remarkable $16 \%$ of ZGs $(39.2 \pm 1.3 \mathrm{ZGs} /$ cell section) were either docked or fusing with the lateral PM, while all the other WT groups showed less than 3\% of ZGs docked (or undergoing exocytosis) onto the lateral PM (ED/saline, $1.6 \pm 0.3$ $\mathrm{ZGs} /$ cell section; $\mathrm{CD} /$ saline, $0.8 \pm 0.2 \mathrm{ZGs} /$ cell section; $\mathrm{CD} / \mathrm{Cch}$, $0.9 \pm 0.2 \mathrm{ZGs} /$ cell section). In contrast, Vamp $8^{-/-}$ED-fed Cchtreated group, despite the great abundance of $Z G$ s, showed very few ZGs (less than 1\%) docked or exocytosing on the lateral PM $(1.1 \pm 0.4 \mathrm{ZGs} /$ cell section), as was also the case with the rest of the Vamp8 $8^{-/}$groups (summarized in Supplemental Figure 2C). Furthermore, in WT ED-fed Cch-treated acini, 56\% of these docked or exocytosing ZGs at the lateral PM occurred at a distance of more than $4 \mu \mathrm{m}$ from the junctional complexes, whereas no lateral exocytosis was observed at such a distance from the junctional complexes with any other groups (including the Vamp8 $8^{-/-} \mathrm{ED} /$ Cch group; summarized in Supplemental Figure 2D). Lateral exocytosis in the WT ED/Cch pancreatic tissues (Figure 6) led to inflammation within the interstitial space, which resulted in disruption of the lateral PM and necrotic changes of the nucleus and intracellular organelles (Figure 7). The fourth feature, therefore, is that ED rendered a substantial portion of the lateral PM receptive to exocytosis, predisposing to pancreatitis, and these events were blocked by VAMP8 deletion.

Lastly, we examined for ZG-ZG fusion events. In WT ED-fed Cch-treated pancreatic tissue (Figure 7), we observed a large number of ZG-ZG fusion events (10.6 \pm 1.1 fusions/cell section; summarized in Supplemental Figure 2E). Here, the magnified images in Figures 6 and 7 show various stages of ZG-ZG fusion, including compound fusions of multiple ZGs, some of which had partially emptied their contents. These ZG-ZG fusion events were blocked by Atp pretreatment (ED/Atp plus Cch, $1.7 \pm 0.6$ fusions/cell section) to the same level as that observed in the ED saline-treated group (1.5 \pm 0.4 fusions/cell section). In contrast, we found a very low number of ZG-ZG fusion events in the Vamp $8^{-/-}$ED-fed Cchtreated group ( $0.5 \pm 0.2$ fusions/cell section). Taken together, the fifth feature is that ED plus Cch treatment induced ZG-ZG fusion that required VAMP8.

VAMP8 ZGs preferentially traffic to the basolateral PM surface. Since VAMP8 deletion interfered with exocytosis at the basal and lateral PM, this would suggest that VAMP8 might be the v-SNARE that traffics the ZGs to these exocytotic sites. We show above that EtOH pretreatment followed by $3 \mu \mathrm{M}$ Cch stimulation predictably evoked basolateral exocytosis. We used this protocol to analyze VAMP8 localization in WT acini by confocal immunofluorescence microscopy. Figure 8 shows that in unstimulated pancreatic acini (KRH/KRH), VAMP8 antibody stained granule structures within the apical poles (adjacent to actin-rich apical lumen) but appeared to be more dispersed. Incubation with $\mathrm{EtOH}$ alone did not show changes in VAMP8 staining (data not shown). After submaximal $(3 \mu \mathrm{M}) \mathrm{Cch}(\mathrm{KRH} / \mathrm{Cch})$ stimulation, the VAMP8-labeled ZGs appeared to be more compact and crowded toward the apical lumen, suggesting that ZG-ZG fusion was taking place. Remarkably, pretreatment with EtOH $(20 \mathrm{mM}, 1 \mathrm{~h})$ followed by submaxi$\mathrm{mal}(3 \mu \mathrm{M}) \mathrm{Cch}(\mathrm{EtOH} / \mathrm{Cch})$ stimulation induced these VAMP8positive structures to be localized toward the basal and lateral PM and much less within the apical pole abutting the apical ductal lumen. This is consistent with VAMP8 promoting exocytosis at the basal PM (Figure 5, C-E) and lateral PM (Figure 6). As a control, $1 \mu \mathrm{M}$ Atp pretreatment blocked both Cch-provoked crowding of VAMP8-labeled ZGs within the apical pole and EtOH/Cchinduced redistribution of VAMP8-labeled ZGs to the basolateral PM (data not shown). 

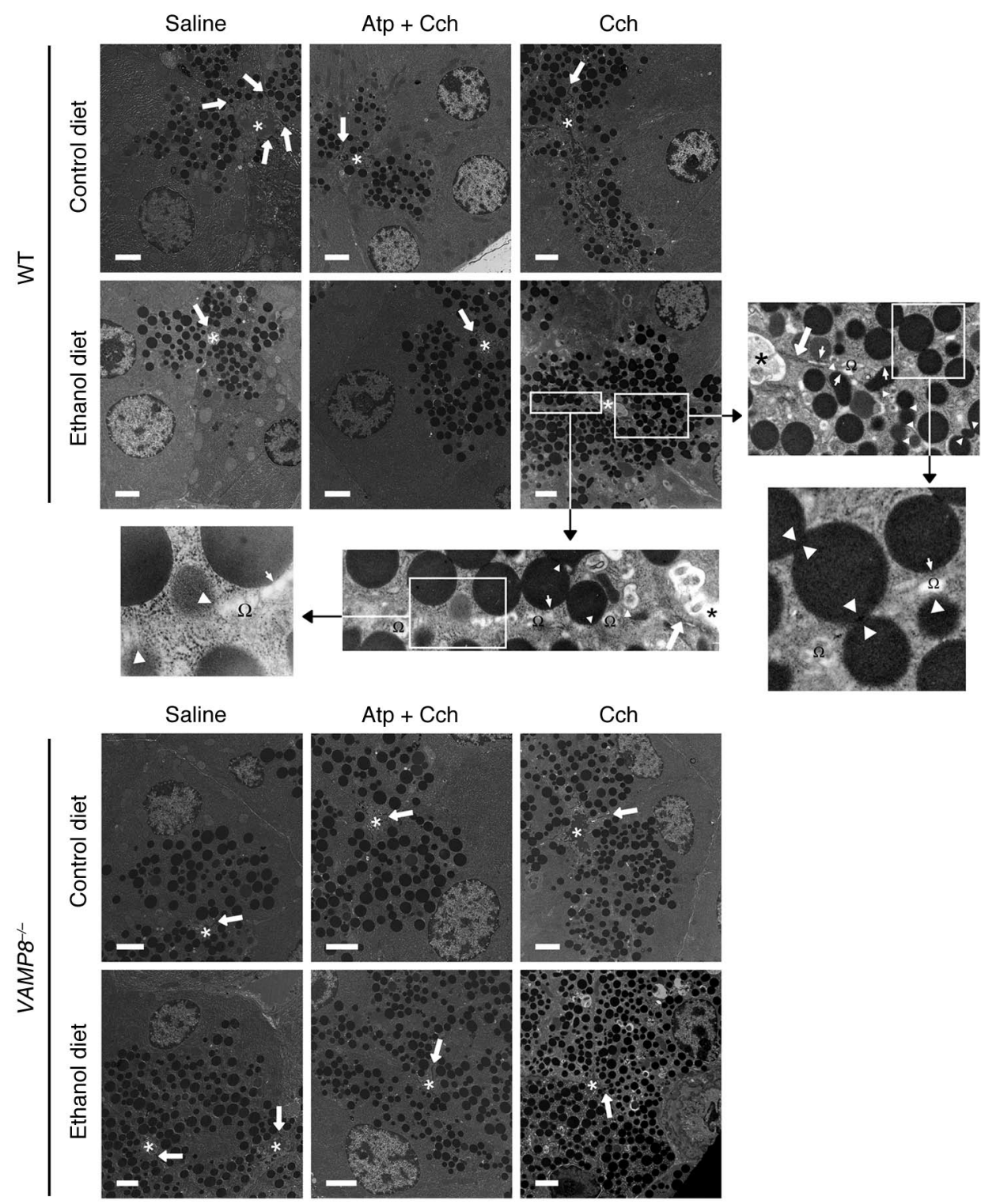

\section{Figure 6}

ED plus Cch stimulation redirects apical exocytosis to the lateral PM to cause pancreatitis, and this requires VAMP8. EM was performed on WT or Vamp8 ${ }^{-/}$ pancreatic tissue from mice on either CD or ED, which were subjected to 5 i.p. injections of saline, Atp $(0.1 \mathrm{mg} / \mathrm{kg} / \mathrm{h})$ followed by Cch $(50 \mu \mathrm{g} / \mathrm{kg} / \mathrm{h})$, or Cch $(50 \mu \mathrm{g} / \mathrm{kg} / \mathrm{h})$ alone. Asterisks indicate the location of the apical ductal lumens, and thick arrows indicate the junctional complexes, which separate the apical lumen from the lateral PM. The highpower magnification of WT ED plus Cch stimulation treatment shows that along the length of the lateral PM we observed ZGs docked onto the lateral PM (thin arrows in insets) and ZGs undergoing exocytosis with the lateral PM (arrowheads; fusion pores were observed in some) into dilated interstitial spaces $(\Omega)$. Numerous homotypic ZG-ZG fusions were noted close to the membrane and deeper in the cytosol (point of membrane fusion indicated by white arrowheads). ZG quantification of these EM data for each strain and treatment was performed on 300 cells from 3 independent experiments in a blinded manner by 2 independent observers, and this analysis is shown in Supplemental Figure 2. Scale bars: $2 \mu \mathrm{m}$.
VAMP8 forms distinct ternary SNARE complexes that mediate basolateral exocytosis and ZG-ZG fusion. We previously reported that basolateral exocytosis in dispersed pancreatic acinar cells stimulated with supramaximal CCK or $20 \mathrm{mM}$ EtOH plus submaximal CCK or Cch (3 $\mu \mathrm{M}$ Cch) involved the SNARE complex Syn-4/SNAP-23/ VAMP and Munc18c (6-8). In order for Syn-4 to become receptive to assembly with SNAP-23 and VAMPs, phosphorylation of Munc18c by PKCa was required to induce displacement of Munc18c and activation of Syn-4 $(6,7)$. Munc18c displaced into the cytosol then underwent proteolytic degradation $(4,6-8)$, which explains the lower levels found in the total lysates. Here, we determined the fate of this basolateral PM SNARE complex in dispersed acini stimulated by these conditions when VAMP8 was deleted (Figure 9A and Supplemental Figure 3A). Under basal conditions (KRH), immunoprecipitated Syn-4 from the PM fraction bound strongly to Munc18c of both WT and Vamp $8^{-/-}$acini, and Syn-4 would not bind cognate SNARE proteins SNAP-23 or VAMPs. In both groups, $20 \mathrm{mM}$ EtOH plus $3 \mu \mathrm{M}$ Cch stimulation caused uni- form reduction of PM Munc18c levels (indicating displacement into the cytosol), which enabled Syn-4 binding to SNAP-23, and these events were not perturbed by the VAMP8 deletion. These initial events rendered the basolateral PM extremely receptive to assembly with ZG VAMPs. Indeed, in WT acini, ZG fusion with the basolateral PM induced assembly with VAMP8, which is consistent with the VAMP8 redistribution to the basolateral PM shown in Figure 8. The absence of VAMP8 in Vamp $8^{-{ }^{--}}$acini prevented this SNARE complex from forming, thus explaining the absence of basolateral exocytosis. It seems that the Syn-4/SNAP-23 complex binding to VAMP2 in the Vamp $8^{-/-}$acini did not increase over that of WT acini despite the higher levels of VAMP2 that resulted from more abundant ZGs in the Vamp8-/- acini.

Since Syn-2 exclusively localizes to the apical PM and has been postulated to mediate apical exocytosis, that is, ZG-apical PM fusion per se $(10,11,31)$, we examined whether endogenous Syn-2 immunoprecipitated from the PM fraction would form complexes with VAMP2 and/or VAMP8 in WT acini (Figure 9B). With $3 \mu \mathrm{M}$ 


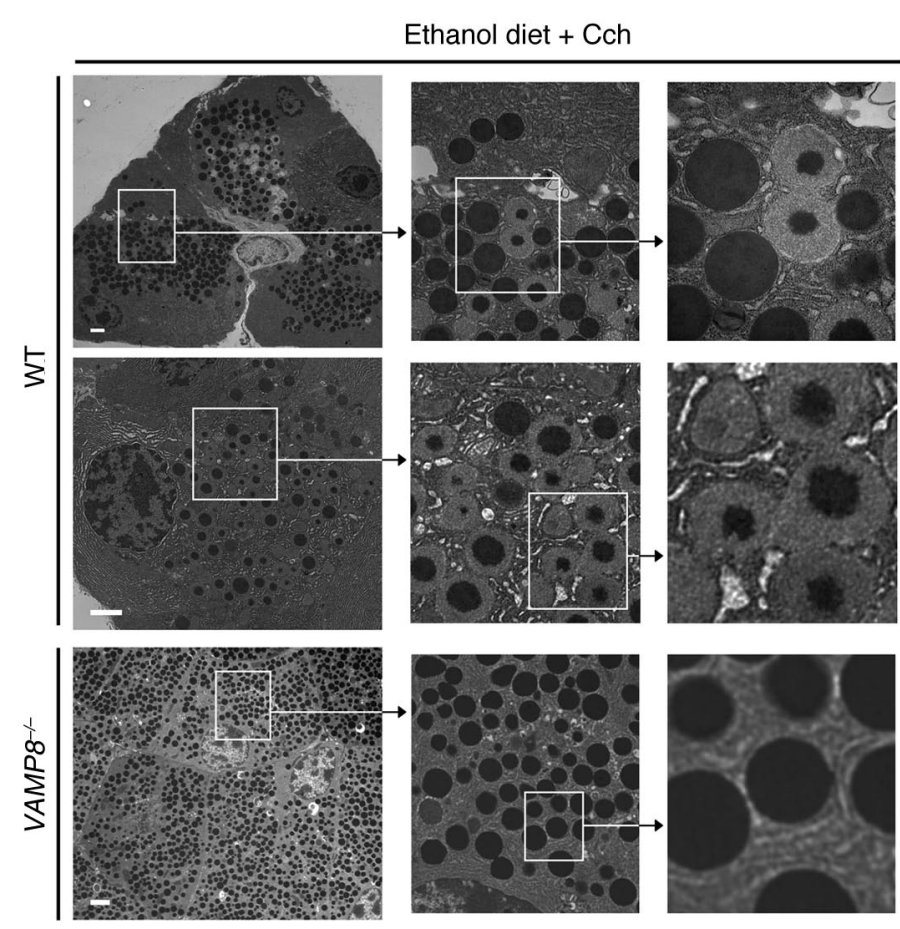

Cch, which stimulated apical exocytosis, Syn-2 did not coprecipitate VAMP8 but did strongly precipitate VAMP2 (and SNAP-23). However, in unstimulated acini (KRH), Syn-2 did not bind VAMP2 or SNAP-23, but instead bound strongly to Munc18b (32). Only upon Cch stimulation was Syn-2 enabled (or activated) to bind VAMP2 and SNAP-23, which was remarkably accompanied by dissociation of Munc18b from the PM. However, after dissociation, Munc18b did not seem to undergo degradation as was observed with Munc18c (4, 6-8) (Figure 9, B and C, and Supplemental Figure 3A). These results suggest that the Syn-2/SNAP-23/VAMP2 SNARE complex mediates apical exocytosis and that VAMP8 may not participate in apical exocytosis per se, hence explaining why apical exocytosis remained intact in VAMP8 acini. Of note, with $20 \mathrm{mM}$ EtOH plus $3 \mu \mathrm{M}$ Cch stimulation, which blocked apical exocytosis, the Syn-2/SNAP-23 complex formed along with Munc18b displacement from the PM, but this did not proceed to full SNARE complex formation with VAMP2.

Lastly, we examined the role of Syn-3 in ZG-ZG fusion (10, 11 ) in WT acini by immunoprecipitating Syn-3 from $Z G$

\section{Figure 8}

VAMP8 is redistributed to the basolateral PM in WT acini after stimulation with EtOH plus Cch. Representative confocal images of VAMP8 localization in dispersed pancreatic acini from WT mice. Acini were preincubated in $\mathrm{KRH}$ or 20 $\mathrm{mM} \mathrm{EtOH}$ for $1 \mathrm{~h}$ and then stimulated with $3 \mu \mathrm{M}$ Cch for 20 min or further incubated for $15 \mathrm{~min}$ with $\mathrm{KRH}$. The acini were then fixed and double-labeled for VAMP8 (red in merged images) and actin (green in merged images). Arrow and arrowhead indicate VAMP8-positive ZG-like structures localized near the basal and lateral PM surfaces, respectively. Scale bars: $10 \mu \mathrm{m}$.

\section{Figure 7}

VAMP8 is involved in ZG-ZG fusion. Further characterization of pancreatic tissues of WT (top 2 rows) and Vamp8 ${ }^{-1-}$ (bottom row) ED-fed rats injected with Cch $(50 \mu \mathrm{g} / \mathrm{kg} / \mathrm{h})$. WT mouse acini showed necrotic spots (pyknotic nuclei, disrupted cytoskeleton, organelle disintegration) and many ZGs undergoing various stages of ZG-ZG fusion (see higher magnification images). Vamp $8^{-1-}$ mice showed a larger number of ZGs filling up the entire cell, but the ZGs were not docked onto the lateral or basal $P M$ and practically no fusion between ZGs was observed. ZG quantification of these EM data for each strain and treatment was performed on 300 cells from 3 independent experiments in a blinded manner by 2 independent observers, and this analysis is shown in Supplemental Figure 2. Scale bars: $2 \mu \mathrm{m}$.

membranes (Figure 9C). In the basal state (KRH), Syn-3, similar to Syn-2, bound strongly to Munc18b (32) and did not bind VAMP8 (or VAMP2). Upon $3 \mu \mathrm{M}$ Cch stimulation (causing sequential ZGZG fusions), and even moreso after $20 \mathrm{mM}$ EtOH plus $3 \mu \mathrm{M}$ Cch (causing ZG-ZG fusion with apical blockade), Syn-3 became able to bind VAMP8 and SNAP-23. Munc18b was again observed to displace from the ZG membranes, particularly with $20 \mathrm{mM} \mathrm{EtOH}$ plus $3 \mu \mathrm{M}$ Cch stimulation. There was no binding of the Syn-3/ SNAP-23 complex to VAMP2. These results suggest that VAMP8 (and not VAMP2) in complex with Syn-3 and SNAP-23 may be the putative SNARE complex mediating ZG-ZG fusion.

\section{Discussion}

The pancreatic acinar cell is an excellent polarized cell model (previously coined the "classic model") to examine distinct exocytic

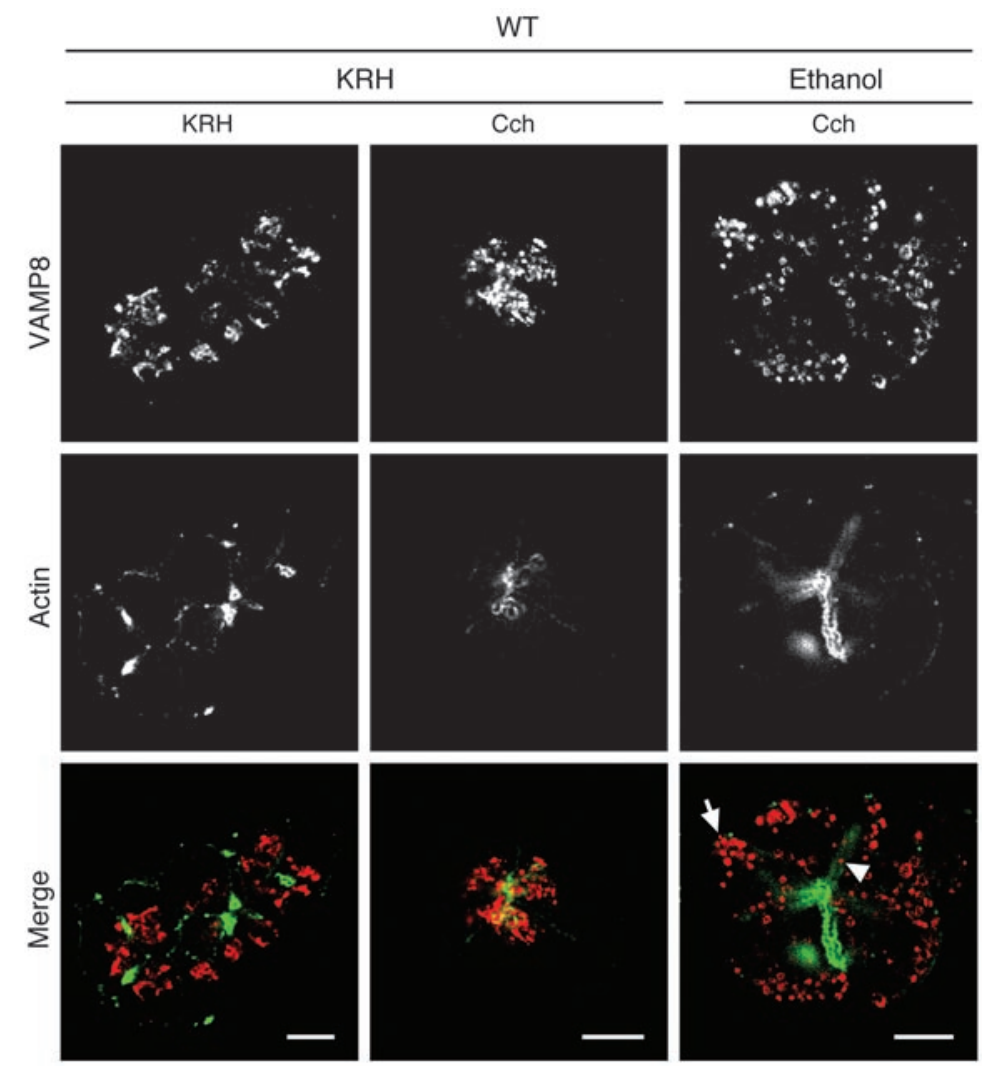



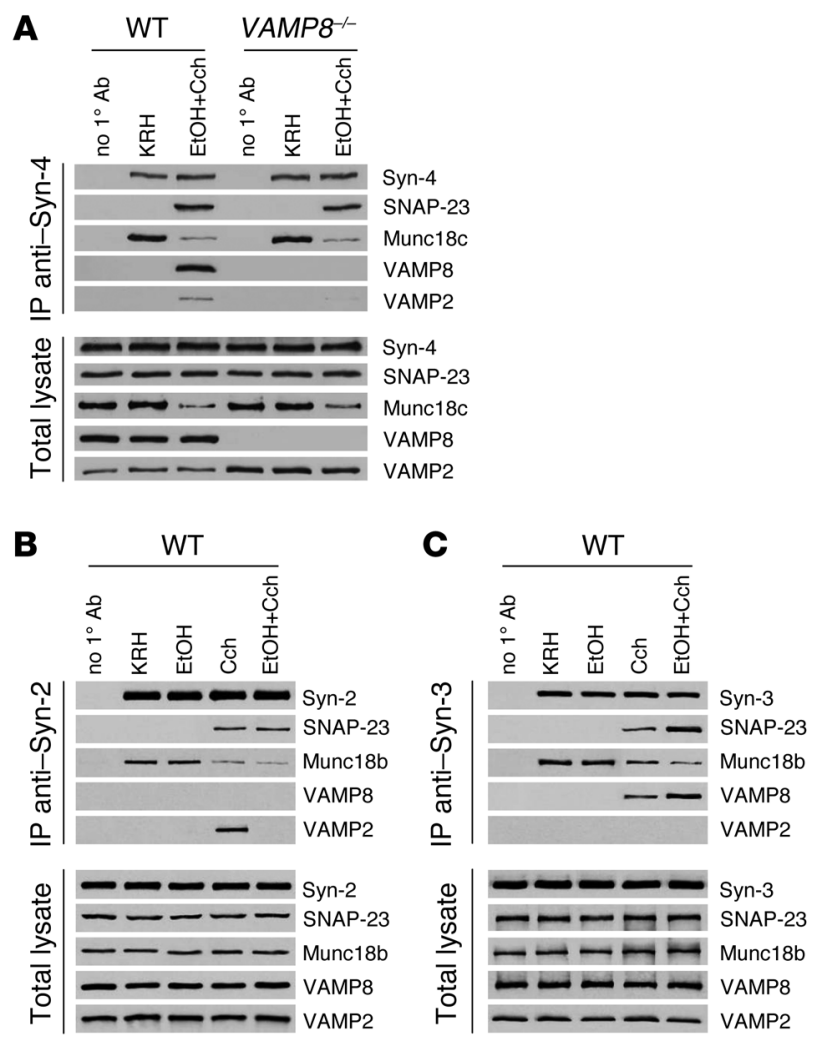

processes, including apical exocytosis, granule-granule fusion, and basolateral exocytosis $(33,34)$. The basis for ZGs to be targeted to these distinct exocytic compartments is dictated by the corollary SNARE hypothesis of compartmental specificity, which includes the distinct SNARE complexes and their cognate Munc18 proteins that regulate their assembly $(9,35,36)$. While apical exocytosis, that is $Z G$ fusion with apical PM, and subsequent sequential ZG-ZG fusions are evoked by physiologic stimulation, pathologic stimulation (supramaximal CCK or Cch; alcohol sensitization to submaximal Cch or CCK stimulation) redirects the exocytosis to the basolateral PM surface, which we have postulated to be a contributing factor to human alcoholic pancreatitis $(6-8,37)$. In this work, we have used the Vamp $8^{-/-}$mouse and employed an alcoholic pancreatitis protocol, simulating the human disease to dissect some of these processes. We were able to elucidate the role of ZG SNARE protein VAMP8 in basolateral exocytosis as an underlying basis for alcoholic pancreatitis and its involvement in ZG-ZG fusion. The following are our major findings, which are summarized in Figure 10.

First, VAMP8 is not required for exocytosis of ZGs with the apical PM per se, which is supported by the following evidence. Submaximal Cch $(3 \mu \mathrm{M})$ remained able to stimulate amylase release from Vamp $8^{-I^{-}}$acini, albeit less than WT acini. FM1-43 imaging showed apical exocytosis could take place at the apical lumen in Vamp8 $8^{--}$acini, but to a lesser extent than in WT acini. EM showed that ZGs packed in the apical poles were reduced in number after Cch stimulation in Vamp $8^{-/-}$acini, resulting in dilation of the apical ductal lumen, as was observed in WT acini. VAMP8 would not bind Syn-2 as we had previously shown (15). Instead, we show that apical exocytosis is likely mediated by apical PM Syn-2 (31) binding to VAMP2, presumably from ZGs docked onto the apical PM.

\section{Figure 9}

VAMP8 forms distinct ternary SNARE complexes that mediate basolateral exocytosis and ZG-ZG fusion. Dispersed acini from WT and $V$ amp $8^{-/-}$mice were treated with the following conditions: control $\mathrm{KRH}$ buffer ( $2 \mathrm{~h}$ ), $\mathrm{KRH}$ buffer ( $1 \mathrm{~h}$ ) followed by $20 \mathrm{mM} \mathrm{EtOH} \mathrm{(1} \mathrm{h),} \mathrm{KRH} \mathrm{buf-}$ fer $(1 \mathrm{~h})$ followed by $3 \mu \mathrm{M}$ Cch $(1 \mathrm{~h})$, or $20 \mathrm{mM} \mathrm{EtOH}(1 \mathrm{~h})$ followed by 3 $\mu \mathrm{M}$ Cch $(1 \mathrm{~h})$. PM and ZG membrane fractions were then prepared from these acini. Protein $(200 \mu \mathrm{g})$ of purified PM was immunoprecipitated with (A) anti-Syn-4 antibodies (WT and $\mathrm{Vamp}^{-/-}$mouse acini) or (B) anti-Syn-2 antibodies (only WT), and $200 \mu$ p protein of the purified ZG membranes was immunoprecipitated with (C) anti-Syn-3 antibodies (WT only). The precipitated proteins were separated on SDS-PAGE and identified with the indicated antibodies. Total lysates ( $8 \mu \mathrm{g}$ protein) serving as input controls showed similar levels of SNARE proteins in the various treatments, except for Munc18c, VAMP2, and VAMP8 in A. These blots are representative of 3 independent experiments with samples performed in duplicate, and analyses are shown in Supplemental Figure 3.

Interestingly, Syn-2 would not form a ternary SNARE complex with VAMP2 and SNAP-23 until after Cch stimulation. Along with Munc18b displacement from the PM, this would strongly suggest that Syn-2 needs to be "activated" by Munc18b $(32,38)$, which presumably involves Munc18b displacement for PM-bound Syn-2, similar to the behavior we have described for Munc18c-Syn-4 interactions (6-8). However, while Munc18c seems to be degraded (4, 6-8), Munc18b levels remained constant after displacement into cytosol. We speculate that there might be unknown Munc18b binding proteins (38) that protect it from degradation or that Munc18c might be more susceptible to as yet unknown acinarspecific cytosolic proteases. The latter possibility is supported by the fact that activated/phosphorylated Munc18c in adipocytes and skeletal muscles is not degraded at all (39). Taken along with our initial report showing that tetanus toxin cleavage of VAMP2 reduced only $30 \%$ of $\mathrm{Ca}^{2+}$-evoked amylase release from permeabilized acini (17), these results suggest that apical exocytosis is likely mediated by VAMP2. The remaining 70\% of secretion in that assay may have been contributed at least in part by basolateral exocytosis, since the external $\mathrm{Ca}^{2+}$ buffer introduced would be evenly distributed throughout the cell. Consistent with these distinct exocytic roles for VAMP2 and VAMP8, a recent report showed these VAMP proteins are contained in distinct $Z G$ populations (18). The efficiency of apical exocytosis in Vamp $8^{-/-}$acini would be expected to be much more reduced but seems to have been partially compensated for by the increased levels of VAMP2. Remarkably, EtOH blockade of Cch-stimulated apical exocytosis was likely due to the inability of the activated Syn-2/SNAP-23 complex to form a ternary complex with VAMP2. EtOH pretreatment, however, did not completely ablate amylase secretion in $\mathrm{Vamp}^{-{ }^{--}}$acini, indicating that other VAMPs may be involved in additional exocytosis events. Although abundant in pancreatic acinar cells, VAMP3 is not enriched in mature ZGs but rather in microsomal fractions, and therefore VAMP3 would not have a direct role in exocytosis (40).

Second, VAMP8 is required for ectopic exocytosis at the basal PM and lateral PM, which occurred in WT acini. In WT acini, thick optical sectioning by epifluorescence FM1-43 imaging was able to capture the infrequent exocytosis at the basal PM, whereas EM allowed for better visualization of lateral exocytosis. Similar to our previous reports $(4,6-8)$, single-ZG exocytosis was observed at restricted sites (usually previously docked sites rather than de novo sites) at the basal PM. These sites were capable of recruit- 


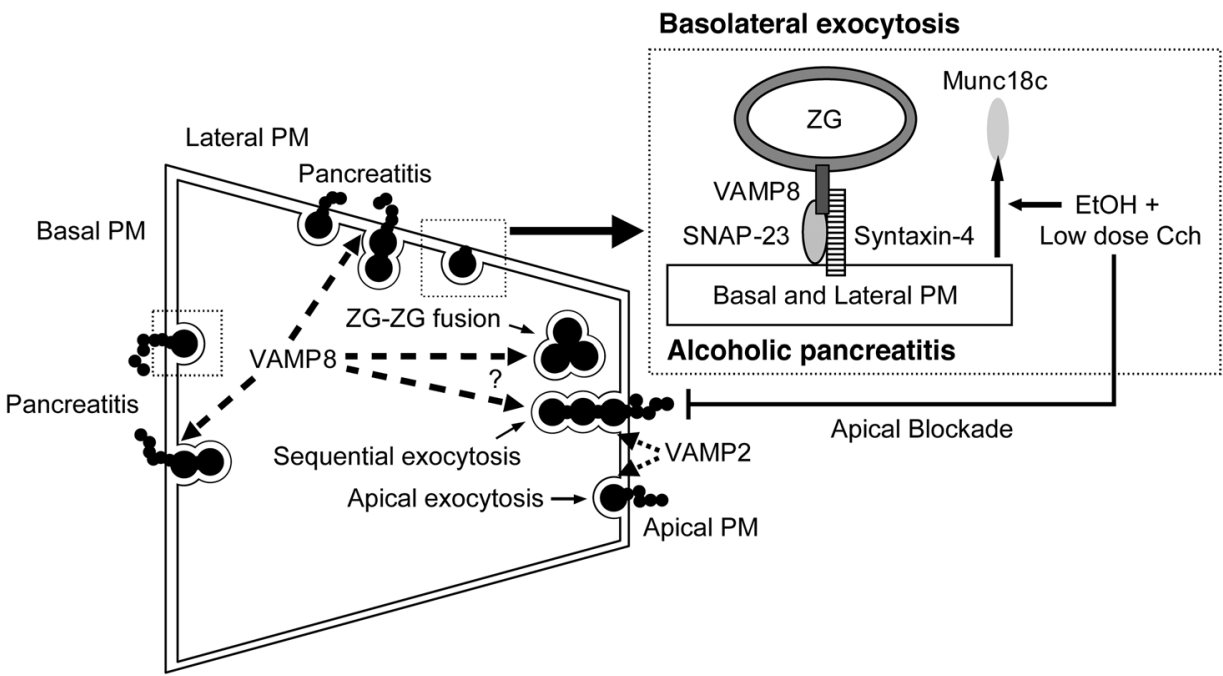

Figure 10

The role of VAMP8 in regulated exocytosis in pancreatic acinar cells and pathologic basolateral exocytosis underlying alcoholic pancreatitis. Chronic exposure to ED followed by postprandial submaximal Cch stimulation causes blockade of apical exocytosis and redirects exocytosis to the basal and lateral $\mathrm{PM}$. Here, EtOH plus low-dose Cch causes Munc18c displacement from the basolateral PM, which activates Syn-4 on the basolateral PM to bind SNAP-23 and VAMP8 from ZGs to form an exocytic SNARE complex capable of mediating basolateral exocytosis. We have postulated that the ensuing secretion of digestive enzymes into the interstitial space could result in pancreatitis. In the absence of VAMP8, assembly of this exocytic complex is prevented, diminishing the contribution of basolateral exocytosis to alcoholic pancreatitis. VAMP8 is also postulated to participate in ZG-ZG fusion, including sequential exocytosis that occurs at the apical and basolateral PM. VAMP2 is postulated to mediate apical exocytosis, that is, ZG fusion with the apical PM.

ing additional single ZGs, but only after long pauses (several min). This inefficient exocytosis at the basal PM is due to the presence of fewer ZGs in the vicinity of the basal PM surface and the location of ZGs deeper in the cell interior, farther from the basal PM in WT acini. In contrast, apical exocytosis is efficient because approximately $70 \%$ of ZGs are packed within the apical poles, which could undergo rapid sequential and compound fusions within just 1-2 $\min (4,13,31,34)$. However, in Vamp $8^{-/-}$acini, the abundant ZGs were also packed toward (but not docked) the basal and lateral PM, where exocytosis appeared to be blocked or reduced. It appears that EtOH rendered the lateral PM even more receptive to exocytosis than the basal PM. Exocytosis at the lateral PM could be more efficient in part because of the large number of ZGs adjacent to the lateral PM. In further support of the role of VAMP8 in basolateral exocytosis, VAMP8 ZGs redistributed to the basal and lateral PM in WT acini after EtOH plus Cch treatment.

Third, basolateral exocytosis is an underlying basis of alcoholic pancreatitis. Whereas exocytosed zymogens into the interstitial spaces could be released into the supernatant in dispersed acini, such zymogens would be trapped within intact pancreatic tissue of the mouse, where the microcirculation is not able to efficiently clear (30). The abundant zymogens retained in the interstitial space become activated to cause damage not only directly but also by recruiting neutrophils and elaborating inflammatory mediators that perpetuate the injury, culminating in increasing severity of pancreatitis $(28,41)$. Our results with in vitro $20 \mathrm{mM}$ EtOH treatment of dispersed acini and an in vivo alcohol diet simulating clinical alcohol intoxication collectively suggest that this mechanism of inducing the basolateral PM surface to become receptive to ectopic exocytosis acts as a susceptibility factor that renders pancreatic acinar cells sensitized to triggering factors (i.e., postprandial cholinergic stimulation) to cause pancreatitis. Although much work has been done to demonstrate the role CCK in pancreatic acinar signaling and pancreatitis using rodent models, it turns out that human pancreatic acinar cells contain little or no CCK receptors and rely more on cholinergic receptors (42) and, consequently, the involvement of cholinergic signaling in alcoholic pancreatitis. This in part provided our rationale for using the ED plus low-dose Cch-induced pancreatitis model, which we nonetheless also compared with the classic model of supramaximal cerulein pancreatitis. Of note, cholinergic signaling in rodent exocrine pancreas is similar in most respects to CCK signaling.

We show that ED sensitized the pancreas to low-dose Cch stimulation, leading to pancreatitis. Some recent work has been done to demonstrate that EtOH very similarly sensitizes the pancreas to low-dose CCK stimulation $(43,44)$. Specifically, an ED sensitized rats to pancreatitis elicited by physiologic doses of CCK8, through the activation of NF- $\mathrm{KB}$, resulting in the upregulation of proinflammatory cytokines and chemokines in the pancreas (43). While the plasma levels of CCK remained unchanged by the $\mathrm{ED}$, the length of the treatment directly correlated with the degree of inflammatory damage (44). Later, the same group showed that NF- $\kappa \mathrm{B}$ activation requires PKC- $\delta$ and $-\varepsilon$ activation; this is attained through $\mathrm{PKC}-\varepsilon$ activation by $\mathrm{EtOH}$, which then collaborates with PKC- $\delta$ activation induced by CCK (44). A similar role and behavior for PKC- $\varepsilon$ activation by EtOH in cooperation with activated PKC- $\delta$ has been described in NG108-15 cells (45) and cultured neural cells (46). In a concentration-dependent manner, EtOH also sensitized acinar cells to cerulein-induced zymogen, trypsin, and chymotrypsin activation (47). Remarkably, EtOH was also shown to inhibit both CCK- and Cch-stimulated amylase release from dispersed acini, where the authors speculated that PKC might be involved (48). In our recent reports, we utilized both models of alcohol diet or pretreatment on submaximal Cch (6) or CCK $(7,8)$ stimulation and showed similar actions on PKC- $\alpha-$ mediated threonine phosphorylation of Munc18c, which caused Munc18c displacement from the PM, enabling SNARE proteins on ZGs and the basolateral membrane to assemble into a complex capable of consummating pathologic ectopic exocytosis at the basolateral surface (6-8). Interestingly, VAMP8 deletion reduced not only the pancreatic tissue injury but also the systemic parameters of disease activity and secondary injury to the lung (a frequent cause of death in alcoholic pancreatitis).

The pancreatic acinar cell is the initial site of injury for the development of pancreatitis, including alcoholic pancreatitis. However, the increased level of severity in this disease can be modulated by 
mediators (TNF- $\alpha$, IL-1, IL-6, and IL-8) $(49,50)$ that are secreted by inflammatory cells (eosinophils, neutrophils, mast cells), in which VAMP8 has recently been shown to be present (51-53). However, in these inflammatory cells, VAMP8 deletion did not interfere with the release of cytokines and chemokines $(52,53)$. In fact, it was VAMP7, and not VAMP8, that was shown to be the putative $\mathrm{v}$-SNARE in eosinophils and neutrophils involved in the secretion of these inflammatory mediators (54). In mast cells, VAMP8 deletion did not affect release of the inflammatory mediators histamine, TNF- $\alpha$, IL-6, IL-4, and MIP-1 $\alpha(52,53)$, although serotonin and cathepsin D secretion were impaired (52). As for platelets, VAMP8 is indeed a primary v-SNARE for release of platelet aggregating factor (51). However, such reduced platelet function would be predicted to increase hemorrhage and thus worsen pancreatitis severity in the Vamp $8^{-/-}$mice, but the opposite was observed in our pancreatitis model, indicating that presence of hemorrhage is attributed to the pancreatitis per se and not to the platelet function. Our results showing lower levels of TNF- $\alpha$, IL-6, and MIP- $1 \alpha$ in Vamp $8^{-/-}$mice in both models of pancreatitis (ED/low-dose Cch; supramaximal cerulein) strongly suggest that their amelioration in pancreatitis severity is attributable to reduced acinar cell injury per se as a consequence of the abrogated basolateral exocytosis.

Nonetheless, there was residual injury in these tissues in ED plus Cch-treated Vamp $8^{-/-}$mice. In fact, the pancreatic tissue trypsin activity in Vamp $8^{-1-}$ mice was remarkably similar to WT mice. This would suggest that cellular mechanisms triggered by the process of alcoholic pancreatitis to cause premature intracellular trypsinogen activation $(2,27)$ were not perturbed by the VAMP8 deletion, which would continue to induce pancreatic injury (55), albeit much less so in the Vamp $8^{-1-}$ mice. However, the more abundant ZGs in Vamp8 $8^{-/-}$acini would have been expected to increase the amount of trypsinogen substrate for activation. Thus, the absence of a further increase in trypsin activity in Vamp $8^{-/-}$acini suggests that VAMP8 deletion may have reduced the contribution of ZGs from being involved in additional undefined pathologic fusion processes such as with lysosomes, which would lead to trypsinogen activation. Alternatively, the activated trypsinogen, particularly in the Vamp $8^{-/-}$acini, may come from sites or sources other than mature ZGs.

Fourth, VAMP8 deletion blocked basolateral exocytosis by preventing basolateral ternary SNARE complex assembly, which reduced the progression and severity of alcoholic pancreatitis. We previously reported that the Munc18c displacement from the basolateral PM in the cytosol was associated with human alcoholic pancreatitis (37). EtOH treatment alone had little effect on Munc18c but in the presence of postprandial cholinergic stimulation caused PKC- $\alpha$-induced threonine phosphorylation of Munc18c, which resulted in Munc18c displacement from basolateral PM-bound Syn-4 (6-8). This specific interaction of Munc18c with Syn-4 in the basolateral PM compartment rendered this PM compartment very receptive to exocytosis by activating Syn-4 into a conformation that enabled binding to SNAP-23 and subsequent assembly with the oncoming ZG-VAMP8, which would then accelerate basolateral exocytosis (36) and ensuing pancreatitis (6-8). VAMP8 deletion did not prevent Munc18c displacement from the basolateral PM nor the subsequent Syn-4 assembly with SNAP-23 but did prevent the completion of a ternary SNARE complex required to consummate membrane fusion. This resulted in abrogated basolateral exocytosis, which reduced very substantially the severity of pancreatitis. We speculated that VAMP2, which was much more abundant in the Vamp $8^{-/-}$acini, would not suffice as a surrogate SNARE complex to mediate basolateral exocytosis. We recognize that these coimmunoprecipitation results represent only snapshots of the behavior of high-affinity stable SNARE complexes. Such SNARE complexes undergo complicated processes of assembly and disassembly during the exocytotic process (9) and may still exhibit some functional redundancy (VAMP2 for VAMP8) that may not be captured by such studies. Nonetheless, our results show that VAMP2 was insufficient to fully compensate for the exocytic defects caused by the VAMP8 deletion. However, VAMP2 complex with Syn-2/SNAP-23 seems sufficient to mediate apical exocytosis, though at a very reduced efficiency possibly because of the abrogated ZG-ZG fusions. Lastly, the increase in VAMP2 in our Vamp $8^{-/-}$would be predicted to increase membrane fusion instead of blocking fusion that we observed, and thus the blockade of the different exocytotic events (ZG-basolateral PM and ZG-ZG fusion) in $V a m p 8^{-/-}$acini cannot be due to the increased VAMP2 levels.

Fifth, the absence of VAMP8 dramatically decreases ZG-ZG fusion events. ZG-ZG fusion is known to occur in pancreatic acinar cells particularly after supramaximal CCK or Cch stimulation (14), and in this study, also with EtOH pretreatment followed by submaximal Cch stimulation. In Vamp $8^{-1-}$ acini, in spite of the extreme abundance of ZGs, ZG-ZG fusion events were infrequent. ZG-ZG fusion contributed to the sequential $Z G$ exocytosis with the $Z G s$ fused with the apical PM, which was observed in WT acini in the FM1-43 epifluorescence imaging study and was shown more clearly via 2 -photon microscopy by Nemoto et al. (13). This enables efficient release of the zymogen cargo (amylase). Here, we show that ZG-ZG fusion probably involves VAMP8 forming a ternary complex with ZG-bound Syn-3 and SNAP-23. This is also supported by the crowding of VAMP8 staining within the apical pole during Cch stimulation. It seems that ZG-ZG fusion mediated by Syn-3 also required Syn-3 activation by Munc18b, as suggested by Munc18b displacement from the ZG membrane and from Syn-3 after submaximal Cch or EtOH plus Cch stimulation. The dramatic reduction of ZG-ZG fusion events in Vamp ${ }^{-/-}$acini would in part explain the reduced FM1-43 fluorescence at the apical pole of the acini and may account for the inefficiency of amylase release, since ZGs would have to fuse individually with the apical PM to release its cargo. However, ZG-apical PM fusion may have been facilitated in the Vamp $8^{-/}$acini as a result of increased VAMP2 levels. This would explain why Cch-stimulated amylase secretion (with corresponding depletion of ZGs in the apical pole) and dilation of the apical lumen in EM of Vamp8 $8^{-/-}$acini were not more reduced, as might have been expected given the reduced sequential ZG-ZG fusions.

In conclusion, our work demonstrates that VAMP8 is the putative secretory granule SNARE protein that targets ZGs to exocytose with the basolateral PM and is also involved in homotypic ZG-ZG fusion. We also demonstrate that basolateral exocytosis mediated by Munc18c-activated VAMP8/Syn-4/SNAP-23 complex formation contributes to the pathogenesis of alcoholic pancreatitis (Figure 10). It is likely that VAMP8 plays similar roles in exocytosis in numerous other exocrine tissues (e.g., salivary and lachrymal glands, prostate, mammary glands, etc.) (20) and some non-exocrine cells (e.g., platelets) (51), which contain an abundance of VAMP8 and its cognate-interacting SNARE proteins.

\section{Methods}

Antibodies and reagents. Antibodies used include those against VAMP8 and SNAP-23 (generated by us) $(12,15)$, Munc18c (a gift from Y. Tamori, Kobe 
University, Kobe, Japan) (4), Munc18b (a gift from V. Olkkonen, National Public Health Institute, Helsinki, Finland) (32, 38), Syn-4 (a gift from J. Pessin, Stony Brook University, Stony Brook, New York, USA), VAMP2 (StressGen), fluorochrome-conjugated (Cy3) secondary antibody (Jackson ImmunoResearch Laboratories), Alexa Fluor 488-conjugated phalloidin (Invitrogen), and Syn-2, Syn-3, and actin (Sigma-Aldrich). Cch, Atp, cerulein, and other chemicals were from Sigma-Aldrich. FM1-43 was from Invitrogen.

Genotyping. The Vamp $8^{+/+}$WT and Vamp $8^{-/-}$mice were generated by us as described previously $(15,20)$. The genotypes of littermates of $\operatorname{Vamp}^{-/-}$and WT mice were determined by PCR using DNA prepared from the tail tips. PCR analysis was carried our as previously described (15).

Animal models. For the ED/low-dose Cch-induced mouse pancreatitis model, WT and Vamp $8^{-/-}$mice (19 g) were pair-fed a liquid diet (BioServ) containing either $\mathrm{EtOH}$ (final concentration of $6 \%$, equivalent to $36 \%$ of total caloric intake) or maltose-dextrin, as previous reported $(6,8)$ and originally described by Lieber-DeCarli (22). Mice were maintained on these diets for 6 weeks. Both WT and Vamp $8^{-/-}$mice from each diet were then randomly distributed into 3 groups of 4 mice each. Each group was treated with 5 successive hourly i.p. injections of either saline, Cch $(50 \mu \mathrm{g} / \mathrm{kg} / \mathrm{h})$, or Atp $(0.1 \mu \mathrm{g} / \mathrm{kg} / \mathrm{h})$ followed by Cch $(50 \mu \mathrm{g} / \mathrm{kg} / \mathrm{h})$. Mice were sacrificed $1 \mathrm{~h}$ after the last injection. For the cerulein-induced mouse pancreatitis model, WT and Vamp $8^{--}(25 \mathrm{~g})$ mice were fasted overnight and randomly distributed into 4 groups of 5 mice each. Each group received 5 hourly i.p. injections containing a supramaximal stimulating dose of cerulein $(50 \mu \mathrm{g} / \mathrm{kg} / \mathrm{h})$ in $0.9 \%$ sodium chloride to elicit secretagogue-induced pancreatitis. Control groups were administered comparable injections of vehicle ( $0.9 \%$ sodium chloride). Animals were sacrificed $1 \mathrm{~h}$ after the last injection. For both models, blood was collected for serum determinations of IL-6, MIP- $1 \alpha$, TNF- $\alpha$, amylase, lipase, and alcohol levels, using IL- 6 and TNF- $\alpha$ assay kits from Cayman Chemical Co., MIP- $1 \alpha$ from R $\&$ D Systems Inc., and $\alpha$-amylase-SL, lipase, and EtOH-L3K assay kits from Diagnostic Chemicals Ltd. as previously described $(6,8)$. Pancreata and lung tissues were obtained for further studies described below. Animal care and all the procedures were approved by the Institutional Animal Care and Use Committees of the University of Toronto.

Histologic evaluation. Pancreatic and lung tissue were graded on a scale of $0-4$ each for edema, hemorrhage, leukocyte infiltration, and necrosis, as previously described $(8,24,25)$. Histologic changes were graded in a blinded manner by 2 independent observers counting the frequency of foci per field seen at $\times 40$ ( 0 , absent; 1 , mild; 2 , moderate; 3 , severe; 4 , overwhelming).

Determination of tissue inflammatory activity and cellular membrane damage. Pancreata (50 mg protein per sample) were harvested for trypsin activity using Boc-Gln-Ala-Arg-MCA substrate from Peptides International as previously reported $(6,8)$. Pancreatic (50 $\mathrm{mg}$ protein) and lung tissue (50 $\mathrm{mg}$ protein) were determined for myeloperoxidase activity as previously reported $(6,8)$. Levels of malondialdehyde (by thiobarbituric acid-reactive substances [TBARS] assay) and lipid hydroperoxides in pancreatic tissue as

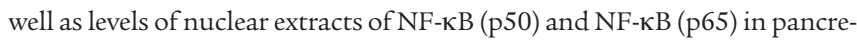
atic and lung tissues were determined using EIA assays (Cayman Chemical Co.) as previously reported $(6,8)$. The total mass of DNA in the pancreatic or lung tissue was used to standardize the units of enzymatic activity.

$E M$. As previous described $(6,8)$, pancreatic samples were fixed with a Karnovsky-based fixative (3.2\% paraformaldehyde, $2.5 \%$ glutaraldehyde in $0.1 \mathrm{M}$ sodium cacodylate buffer with $5 \mathrm{mM} \mathrm{CaCl}_{2}$, pH 6.5) for $1 \mathrm{~h}$, osmicated with $1 \% \mathrm{OsO}_{4}$ for $30 \mathrm{~min}$, and pre-embedded with $1 \%$ uranyl acetate for $1 \mathrm{~h}$. The tissues were then dehydrated and infiltrated with Epon 812 resin at $60^{\circ} \mathrm{C}$ for $48 \mathrm{~h}$. Polymerized blocks were ultra-thin sectioned $(\sim 80$ $\mathrm{nm}$ ) using a Reichert Ultracut E microtome mounted on 200 mesh copper grids and stained with uranyl acetate followed by lead citrate. Samples were then examined using a Hitachi $\mathrm{H} 7000$ transmission electron microscope (Hitachi Ltd.) at an accelerating voltage of $75 \mathrm{kV}$. Ultrastructural analysis and quantification of ZGs were performed as previously described $(6,8)$ on random micrograph sections showing the full face of the acinus, where the apical lumen and junctional complexes were clearly identified along with basally located nuclei (as shown in Figures 7 and 8). All of the ZGs of the cells of these single EM sections were counted in a blinded manner by 2 independent observers. Quantitative analysis of ZG distribution and apical lumen surface areas were measured using NIH ImageJ software.

Dispersed acini preparation and amylase secretion. The preparation of isolated pancreatic acini from WT and Vamp $8^{-1-}$ mice was performed by a mechanical and enzymatic dissociation technique. The acini $\left(\sim 10^{6} \mathrm{cells}\right)$ were stimulated with the indicated agonists for $1 \mathrm{~h}$ at $37^{\circ} \mathrm{C}$. Amylase released into the supernatant and amylase content of the acini pellet were determined by a colorimetric method. Total amylase was defined as the summation of the amylase content in the respective cell pellet plus supernatant, and the amylase secreted into the supernatant was expressed as a percentage of total amylase or as arbitrary units. The data obtained were collected from 3 separate portions of acini per experiment (from 1 mouse) of 5 different acini preparations, which were then pooled $(n=15)$ and analyzed by Student's $t$ test, with significance determined to be $P<0.05$.

Measurement of $\left[\mathrm{Ca}^{2+}\right]_{i}$ in acinar cell suspension. Dispersed pancreatic acini from WT and Vamp $8^{-/-}$mice were loaded at $37^{\circ} \mathrm{C}$ with $2 \mu \mathrm{M}$ Fura 2-AM for $30 \mathrm{~min}$ in solution Q containing (in $\mathrm{mM}$ ) $120 \mathrm{NaCl}, 20 \mathrm{HEPES}, 5 \mathrm{KCl}$, $1 \mathrm{MgCl}_{2}, 1 \mathrm{CaCl}_{2}, 10$ sodium pyruvate, 10 ascorbate, and 10 glucose as well as $0.1 \%$ BSA and $0.01 \%$ soybean trypsinogen inhibitor. After washing, acini were resuspended in the same solution and fluorescence was measured in a stirred cuvette at $37^{\circ} \mathrm{C}$ in a Hitachi F-2000 (Hitachi Ltd.) spectrofluorometer with excitation at 340 and $380 \mathrm{~nm}$ and emission at $510 \mathrm{~nm}$. Ratiometric calculations of $\left[\mathrm{Ca}^{2+}\right]_{i}$ were performed as previously described (56) using a $K_{D}$ of $224 \mathrm{nM}$.

FM1-43 epifluorescence imaging of exocytosis. Single ZG exocytosis was visualized in real-time using this imaging assay technique as previously reported $(4,6-8,29)$. Dispersed acini were plated on glass coverslips and mounted in a heated chamber kept at $37^{\circ} \mathrm{C}$. The cells were then incubated in $2 \mu \mathrm{M}$ FM1-43 $\left(15 \mathrm{~min}, 37^{\circ} \mathrm{C}\right)$ until a stable basal fluorescence staining of the acinar PM was attained. Imaging of the cells was carried out on a Nikon TE2000E inverted microscope imaging system (Nikon) with a high numerical aperture lens (1.45) executing a greater light cone that enabled a thinner and higher resolution optical section. Fluorescence images of the FM1-43-stained cells were obtained with 490-/20-nm excitation provided by a monochromator (Tills Photonics) and 617-/73-nm emission filters, with image acquisition at 1 -s exposure $(1 \mathrm{~Hz})$ using an ORCA-ER CCD camera (Hamamatsu). We determined the size and intensity of the FM1-43 fluorescence within indicated regions of interest on the $x-y$ axes to monitor ZG exocytosis occurring at the different sites of the acinar cell. Quantitative analysis of fluorescent signal of individual hot spots on the PM was measured using the Compix Simple PCI (C-Imaging) and ImageJ software. The intensity of each hot spot was normalized to the intensity of the PM adjacent to it.

Confocal immunofluorescence microscopy. Confocal immunofluorescence microscopy was performed as previously described (4, 6-8). Dispersed acini were plated on glass coverslips, fixed with $4 \%$ paraformaldehyde, and rinsed in PBS for $5 \mathrm{~min}$ followed by $10 \mathrm{~min}$ in $100 \mathrm{mM}$ glycine. The acini were then blocked with $5 \%$ normal goat serum with $0.1 \%$ saponin for $0.5 \mathrm{~h}$ at $25^{\circ} \mathrm{C}$. The cells were then washed and incubated with VAMP8 antibody (1:100) for $1 \mathrm{~h}$ at $25^{\circ} \mathrm{C}$, followed by a mixture of fluorochrome-conjugated (Cy3) anti-rabbit antibody $(1: 1,000)$ and Alexa Fluor 488-conjugated phalloidin (1:500) for $1 \mathrm{~h}$ at $25^{\circ} \mathrm{C}$. The coverslips were mounted on slides with DAKO Fluorescence Mounting Medium and examined by a laser scanning 
confocal imaging system (Zeiss LSM510) equipped with LSM software version 5.00 (Carl Zeiss).

Subcellular fractionation. Isolated pancreatic acini were subjected to the indicated agonist stimulation (Figure 9) and then terminated by ice-cold $\mathrm{KRH}$ buffer. The acini were then pelleted by centrifugation $\left(300 \mathrm{~g}, 4^{\circ} \mathrm{C}\right)$. PM fractionation was obtained by sucrose density gradient centrifugation as previously described $(4,6-8)$, with sucrose buffer composed of $0.3 \mathrm{M}$ sucrose, $0.01 \%$ soybean trypsin inhibitor, $0.5 \mathrm{M} \mathrm{PMSF}$, and $5 \mathrm{mM}$ $\beta$-mercaptoethanol. Briefly, acini were homogenized in a Potter-Elvehjem homogenizer, followed by a 5 -min centrifugation $\left(14,000 \mathrm{~g}, 4^{\circ} \mathrm{C}\right)$ to separate the nuclei pellets from supernatants. The supernatant fractions were centrifuged $\left(15 \mathrm{~min}, 14,000 \mathrm{~g}, 4^{\circ} \mathrm{C}\right)$ to separate the $\mathrm{ZG}$ pellets, and the resulting supernatants were subjected to ultracentrifugation $(3 \mathrm{~h}, 39,000 \mathrm{~g}$, $4^{\circ} \mathrm{C}$ ) to obtain the membrane pellet and cytosol supernatant fractions. ZG and ZG membranes were prepared as previously described $(11,17)$. Briefly, purified ZGs were resuspended in $0.17 \mathrm{M} \mathrm{NaCl}$ and $Z G$ membranes obtained by osmotic lysis with $0.15 \mathrm{M} \mathrm{NaHCO}_{3}, \mathrm{pH}$ 7.8. ZG membranes were pelleted by ultracentrifugation $\left(30 \mathrm{~min}, 100,000 \mathrm{~g}, 4^{\circ} \mathrm{C}\right)$, washed in $0.25 \mathrm{M} \mathrm{NaBr}$ to rid of peripherally adhering proteins, and resuspended in lysis buffer in the presence of $1 \%$ Triton X-100.

Immunoprecipitation. Purified PM and ZG membranes containing equal amounts of protein were clarified by centrifugation $(12000 \mathrm{~g}, 10 \mathrm{~min})$ in the presence of $1 \%$ Triton X-100. The resulting supernatants, precleared for $40 \mathrm{~min}$ using $40 \mu \mathrm{l}$ of $50 \%$ suspension of Protein G-Sepharose beads (Pharmacia Biotech), were incubated with Syn-4, Syn-2, or Syn-3 antibody $(1 \mathrm{~h})$. Immunocomplexes were captured by rotating the samples for $1 \mathrm{~h}$ at $4^{\circ} \mathrm{C}$ with $40 \mu \mathrm{l}$ of Protein G-Sepharose beads, which were then washed 4 times with lysis buffer containing $1 \mathrm{mM} \mathrm{Na}_{3} \mathrm{VO}_{4}$. Protein content of all samples (total lysate and immunoprecipitated proteins) was determined by BCA method, and equal amounts of these samples were dissolved in Laemmli buffer, boiled for $5 \mathrm{~min}$, separated on SDSPAGE, and transferred to nitrocellulose membranes (Bio-Rad). Separated proteins were immunodecorated and identified by the indicated primary antibodies and visualized with enhanced chemiluminescence (Amersham Biosciences). Quantification was performed by densitometry using the ImageJ software.

Statistics. All data are presented as mean \pm SD. Statistical analysis was done by Student's t test, but for analysis of ZG distribution data, the Mann-Whitney $U$ test (a nonparametric test) was used to determine significant differences between any 2 experimental groups. Significance was assumed at a $P$ value of less than 0.05 .

\section{Acknowledgments}

This work was supported by grants to H.Y. Gaisano from the U.S. Army Medical Research Acquisition Activity (W81XWH-07-10307) and the NIH (R21 AA015579-01A1) and by an equipment grant from the Banting and Best Diabetes Center (University of Toronto). We thank S. Sugita for critically reading this paper.

Received for publication December 5, 2007, and accepted in revised form April 30, 2008.

Address correspondence to: Herbert Y. Gaisano, University of Toronto, Room 7226, Medical Science Building, 1 King's College Circle, Toronto, Ontario M5S 1A8, Canada. Phone: (416) 9781526; Fax: (416) 978-8765; E-mail: herbert.gaisano@utoronto.ca.
1. Purohit, V., Russo, D., Salin, M., and Brown, R. 2003. Mechanisms of alcoholic pancreatitis: introduction and summary of the symposium. Pancreas. 27:281-285

2. Saluja, A.K., and Bhagat, L. 2003. Pathophysiology of alcohol-induced pancreatic injury. Pancreas. 27:327-331.

3. Pandol, S.J., Gukovsky, I., Satoh, A., Lugea, A., and Gukovskaya, A.S. 2003. Animal and in vitro models of alcoholic pancreatitis: role of cholecystokinin. Pancreas. 27:297-300.

4. Gaisano, H.Y., et al. 2001. Supramaximal cholecystokinin displaces Munc18c from the pancreatic acinar basal surface, redirecting apical exocytosis to the basal membrane. J. Clin. Invest. 108:1597-1611.

5. Bedford, D., O'Farrell, A., and Howell, F. 2006. Blood alcohol levels in persons who died from accidents and suicide. Ir. Med. J. 99:80-83.

6. Cosen-Binker, L.I., Lam, P.P., Binker, M.G., and Gaisano, H.Y. 2007. Alcohol-induced protein kinase Calpha phosphorylation of Munc18c in carbacholstimulated acini causes basolateral exocytosis. Gastroenterology. 132:1527-1545.

7. Cosen-Binker, L.I., et al. 2007. Alcohol/cholecystokinin-evoked pancreatic acinar basolateral exocytosis is mediated by protein kinase C alpha phosphorylation of Munc18c. J. Biol. Chem. 282:13047-13058.

8. Lam, P.P., Cosen Binker, L.I., Lugea, A., Pandol, S.J., and Gaisano, H.Y. 2007. Alcohol redirects CCKmediated apical exocytosis to the acinar basolateral membrane in alcoholic pancreatitis. Traffic. 8:605-617.

9. Rizo, J., and Sudhof, T.C. 2002. Snares and Munc18 in synaptic vesicle fusion. Nat. Rev. Neurosci. 3:641-653.

10. Gaisano, H.Y. 2000. A hypothesis: SNARE-ing the mechanisms of regulated exocytosis and pathologic membrane fusions in the pancreatic acinar cell. Pancreas. 20:217-226.

11. Gaisano, H.Y., et al. 1996. Distinct cellular loca- tions of the syntaxin family of proteins in rat pancreatic acinar cells. Mol. Biol. Cell. 7:2019-2027.

12. Gaisano, H.Y., Sheu, L., Wong, P.P., Klip, A., and Trimble, W.S. 1997. SNAP-23 is located in the basolateral plasma membrane of rat pancreatic acinar cells. FEBS Lett. 414:298-302.

13. Nemoto, T., et al. 2001. Sequential-replenishment mechanism of exocytosis in pancreatic acini. Nat. Cell Biol. 3:253-258.

14. Scheele, G., Adler, G., and Kern, H. 1987. Exocytosis occurs at the lateral plasma membrane of the pancreatic acinar cell during supramaximal secretagogue stimulation. Gastroenterology. 92:345-353.

15. Wang, C.C., et al. 2004. A role of VAMP8/endobrevin in regulated exocytosis of pancreatic acinar cells. Dev. Cell. 7:359-371.

16. Gaisano, H.Y., et al. 1996. The vesicle-associated membrane protein family of proteins in rat pancreatic and parotid acinar cells. Gastroenterology. 111:1661-1669.

17. Gaisano, H.Y., Sheu, L., Foskett, J.K., and Trimble, W.S. 1994. Tetanus toxin light chain cleaves a vesicle-associated membrane protein (VAMP) isoform 2 in rat pancreatic zymogen granules and inhibits enzyme secretion. J. Biol. Chem. 269:17062-17066.

18. Weng, N., Thomas, D.D., and Groblewski, G.E. 2007. Pancreatic acinar cells express vesicle-associated membrane protein 2 - and 8 -specific populations of zymogen granules with distinct and overlapping roles in secretion. J. Biol. Chem. 282:9635-9645.

19. Antonin, W., Holroyd, C., Tikkanen, R., Honing, S., and Jahn, R. 2000. The R-SNARE endobrevin/ VAMP-8 mediates homotypic fusion of early endosomes and late endosomes. Mol. Biol. Cell. 11:3289-3298.

20. Wang, C.C., et al. 2007. VAMP8/endobrevin as a general vesicular SNARE for regulated exocytosis of the exocrine system. Mol. Biol. Cell. 18:1056-1063.

21. Hanck, C., and Whitcomb, D.C. 2004. Alcoholic pancreatitis. Gastroenterol. Clin. North Am. 33:751-765.

22. Lieber, C.S., and DeCarli, L.M. 1994. Animal mod- els of chronic ethanol toxicity. Methods Enzymol. 233:585-594.

23. Saluja, A.J., and Bhagat, L. 2003. Pancreatitis and associated lung injury: when MIF miffs. Gastroenterology. 124:844-847.

24. Cosen-Binker, L.I., Binker, M.G., Cosen, R., Negri, G., and Tiscornia, O. 2006. Relaxin prevents the development of severe acute pancreatitis. World J. Gastroenterol. 12:1558-1568.

25. Cosen-Binker, L.I., Binker, M.G., Cosen, R., Negri, G., and Tiscornia, O. 2006. Influence of nitric oxide-donating nonsteroidal anti-inflammatory drugs on the evolution of acute pancreatitis. Shock. 25:190-203.

26. Girotti, A.W. 1998. Lipid hydroperoxide generation, turnover, and effector action in biological systems. J. Lipid Res. 39:1529-1542.

27. Gorelick, F.S. 2003. Alcohol and zymogen activation in the pancreatic acinar cell. Pancreas. 27:305-310.

28. Sutton, R., et al. 2003. Signal transduction, calcium and acute pancreatitis. Pancreatology. 3:497-505.

29. Cochilla, A.J., Angleson, J.K., and Betz,W.J. 1999. Monitoring secretory membrane with FM1-43 fluorescence. Annu. Rev. Neurosci. 22:1-10.

30. Fernandez-del Castillo, C., Schmidt, J., Warshaw, A.L., and Rattner, D.W. 1994. Interstitial protease activation is the central event in progression to necrotizing pancreatitis. Surgery. 116:497-504.

31. Pickett, J.A., Thorn, P., and Edwardson, J.M. 2005. The plasma membrane Q-SNARE syntaxin 2 enters the zymogen granule membrane during exocytosis in the pancreatic acinar cell. J. Biol. Chem. 280:1506-1511.

32. Kauppi, M., Wohlfahrt, G., and Olkkonen, V.M. 2002. Analysis of the Munc18b-syntaxin binding interface. Use of a mutant Munc18b to dissect the functions of syntaxins 2 and 3. J. Biol. Chem. 277:43973-43979.

33. Palade, G.E. 1975. Intracellular aspects of the process of protein synthesis. Science. 189:347-358.

34. Pickett, J.A., and Edwardson, J.M. 2006. Compound 
exocytosis: mechanisms and functional significance. Traffic. 7:109-116.

35. McNew, J.A., et al. 2000. Compartmental specificity of cellular membrane fusion encoded in SNARE proteins. Nature. 407:153-159.

36. Shen, J., Tareste, D.C., Paumet, F., Rothman, J.E., and Melia, T.J. 2007. Selective activation of cognate SNAREpins by Sec1/Munc18 proteins. Cell. 128:183-195.

37. Gaisano, H.Y., Sheu, L., and Whitcomb, D. 2004. Alcoholic chronic pancreatitis involves displacement of Munc18c from the pancreatic acinar basal membrane surface. Pancreas. 28:395-400.

38. Lam, P.P., et al. 2007. A cytosolic splice variant of Cab45 interacts with Munc18b and impacts on amylase secretion by pancreatic acini. Mol. Biol. Cell. 18:2473-2480.

39. Umahara, M., et al. 2008. Tyrosine phosphorylation of Munc18c regulates platelet-derived growth factor-stimulated glucose transporter 4 translocation in 3T3L1 adipocytes. Endocrinology. 149:40-49.

40. Sengupta, D., Gumkowski, F.D., Tang, L.H., Chilcote, T.J., and Jamieson, J.D. 1996. Localization of cellubrevin to the Golgi complex in pancreatic acinar cells. Eur. J. Cell Biol. 70:306-314.

41. Gukovskaya, A.S., et al. 2002. Neutrophils and NADPH oxidase mediate intrapancreatic trypsin activation in murine experimental acute pancreati- tis. Gastroenterology. 122:974-984.

42. Owyang, C., and Logsdon, C.D. 2004. New insights into neurohormonal regulation of pancreatic secretion. Gastroenterology. 127:957-969.

43. Pandol, S.J., et al. 1999. Ethanol diet increases the sensitivity of rats to pancreatitis induced by cholecystokinin octapeptide. Gastroenterology. 117:706-716

44. Satoh, A., Gukovskaya, A.S., Reeve, J.R., Jr., Shimosegawa, T., and Pandol, S.J. 2006. Ethanol sensitizes NF-kappaB activation in pancreatic acinar cells through effects on protein kinase C-epsilon. Am.J. Physiol. Gastrointest. Liver Physiol. 291:G432-G438.

45. Gordon, A.S., Yao, L., Wu, Z.L., Coe, I.R., and Diamond, I. 1997. Ethanol alters the subcellular localization of delta- and epsilon protein kinase $\mathrm{C}$ in NG108-15 cells. Mol. Pharmacol. 52:554-559.

46. Messing, R.O., Petersen, P.J., and Henrich, C.J. 1991. Chronic ethanol exposure increases levels of protein kinase $\mathrm{C}$ delta and epsilon and protein kinase C-mediated phosphorylation in cultured neural cells. J. Biol. Chem. 266:23428-23432.

47. Lu, Z., Karne, S., Kolodecik, T., and Gorelick, F.S. 2002. Alcohols enhance caerulein-induced zymogen activation in pancreatic acinar cells. Am. J. Physiol. Gastrointest. Liver Physiol. 282:G501-G507.

48. Nakamura, T., et al. 1991. Effect of ethanol on pancreatic exocrine secretion in rats. Pancreas. 6:571-577.
49. Denham, W., et al. 1997. Gene targeting demonstrates additive detrimental effects of interleukin 1 and tumor necrosis factor during pancreatitis. Gastroenterology. 113:1741-1746.

50. Norman, J. 1998. The role of cytokines in the pathogenesis of acute pancreatitis. Am. J. Surg. 175:76-83.

51. Ren, Q., et al. 2007. Endobrevin/VAMP-8 is the primary $\mathrm{v}$-SNARE for the platelet release reaction. Mol. Biol. Cell. 18:24-33.

52. Puri, N., and Roche, P.A. 2008. Mast cells possess distinct secretory granule subsets whose exocytosis is regulated by different SNARE isoforms. Proc. Natl. Acad. Sci. U. S. A. 105:2580-2585.

53. Tiwari, N., et al. 2008. VAMP-8 segregates mast cell preformed mediator exocytosis from cytokine trafficking pathways. Blood. 111:3665-3674.

54. Logan, M.R., et al. 2006. A critical role for vesicleassociated membrane protein-7 in exocytosis from human eosinophils and neutrophils. Allergy. 61:777-784.

55. Steer, M.L., and Meldolesi, J. 1987. The cell biology of experimental pancreatitis. N. Engl. J. Med. 316:144-150.

56. Grynkiewicz, G., Poenie, M., and Tsien, R.Y. 1985. A new generation of $\mathrm{Ca} 2+$ indicators with greatly improved fluorescence properties. J. Biol. Chem. 260:3440-3450. 